\title{
RESEARCH
}

\section{SOX30 is a prognostic biomarker and chemotherapeutic indicator for advanced-stage ovarian cancer}

Fei Han 1,*, Wen-bin Liu1,*, Jian-jun Li², Ming-qian Zhang³, Jun-tang Yang1, Xi Zhang1, Xiang-lin Hao1, Li Yin1, Cheng-yi Mao', Xiao Jiang1 , Jia Cao ${ }^{1}$ and Jin-yi Liu ${ }^{1}$

${ }^{1}$ Institute of Toxicology, College of Preventive Medicine, Army Medical University, Chongqing, China 2Department of Oncology, Southwest Hospital, Army Medical University, Chongqing, China

32Department of Emergency, Yan'an Hospital, Kunming Medical University, Kunming, Yunnan Province, China

${ }^{4}$ Department of Pathology, Daping Hospital, Army Medical University, Chongqing, China

Correspondence should be addressed to J Cao or J Liu: caojia1962@126.com or jinyiliutmmu@163.com

*(F Han and W Liu contributed equally to this work)

\begin{abstract}
New potential biomarkers and therapeutic targets for ovarian cancer should be identified. The amplification in chromosomal region 5q31-5q35.3 exhibits the strongest correlation with overall survival (OS) of ovarian cancer. SOX30 coincidentally located at this chromosomal region has been determined as a new important tumor suppressor. However, the prognostic value, role and mechanism of SOX30 in ovarian cancer are unexplored. Here, we reveal that SOX30 is frequently overexpressed in ovarian cancer tissues and is associated with clinical stage and metastasis of ovarian cancer patients. High SOX30 expression predicts better OS and acts as an independent prognostic factor in advanced-stage patients, but is not associated with OS in early-stage patients. Based on the survival analyses, the advanced-stage patients with high SOX30 expression can receive platin- and/or taxol-based chemotherapy, whereas they should not receive chemotherapy containing gemcitabine or topotecan. Functionally, SOX30 strongly inhibits tumor cell migration and invasion in intro and suppresses tumor metastasis in vivo. SOX30 regulates some markers (E-CADHERIN, FIBRONECTIN, N-CADHERIN and VIMENTIN) and prevents the characteristics of epithelial-mesenchymal transition (EMT). SOX30 transcriptionally regulates the expression of E-CADHERIN, FIBRONECTIN and N-CADHERIN by binding to their promoters. Restoration of E-CADHERIN and/or N-CADHERIN when overexpressing SOX30 significantly reduces the anti-metastatic role of SOX30. Indeed, chemotherapy treatment containing platin or gemcitabine combined with SOX30 expression influences tumor cell metastasis and the survival of nude mice differently, which is closely associated with EMT. In conclusion, SOX30 antagonizes tumor metastasis by preventing EMT process that can be used to predict survival and incorporated into chemotherapeutics of advanced-stage ovarian cancer patients.
\end{abstract}
Key Words
- prognostic factor
- chemotherapy
- tumor metastasis
- epithelial-mesenchymal transition
- transcriptional regulation
- ovarian cancer

Endocrine-Related Cancer (2019) 26, 303-319 (c) 2019 Society for Endocrinology Published by Bioscientifica Ltd. Printed in Great Britain 


\section{Introduction}

Ovarian cancer is the seventh leading cause of cancerrelated death, and the most lethal gynecologic cancer among women worldwide (Ferlay et al. 2013, Siegel et al. 2013). Most ovarian cancer patients are diagnosed as clinical advanced stage (stage III and IV) due to lack of susceptible detection at clinical early stage (stage I and II) (Verhaak et al. 2013). Although there have been advances in surgery and chemotherapy, only about $40 \%$ patients can survive 5 years after diagnosis (Vaughan et al. 2011, Siegel et al. 2016). The initial platinumtaxane chemotherapy after surgery produces a response rate of over $80 \%$ in ovarian cancer patients, but most of these women will relapse and die due to drug resistance progressively (Kartalou \& Essigmann 2001, Marsh 2009, Tsofack et al. 2013, Dong et al. 2016). Prognostic factors can be used to predict the outcome of patients and determine the most appropriate therapy for specific patients. At present, the prognosis is mainly based on clinical stage, histological grade, debulking surgery and platinum-taxane sensitivity in ovarian cancer. Although these are powerful prognosticators, their roles are still limited. Moreover, systemic chemotherapy has got an increasingly key role in effective treatment of ovarian cancer patients, especially the patients at advanced stage. However, the challenge is to determine which of these patients would most benefit from specifically chemotherapeutic treatment. Therefore, identification of new prognostic biomarkers and chemotherapeutic indicators is of great importance to improve therapeutic methods and prolong the survival of patients with ovarian cancer.

Sox30, a member of Sox transcription factor, is always considered to be involved in gonadal development (Osaki et al. 1999, Ballow et al. 2006, Han et al. 2010, 2014). Very recently, SOX30 has been demonstrated as a novel tumor suppressor in human lung cancer, bladder cancer and colon cancer (Han et al. 2015a, 2018, Guo et al. 2017, Liu et al. 2018). However, the clinical prognostic significance and functional role of SOX30 have not been clarified in ovarian cancer. Previous studies have identified that the amplification in chromosomal region 5q31-5q35.3 exhibits the strongest correlation with overall survival (OS) of advanced-stage ovarian cancer (Birrer et al. 2007, Wei et al. 2013). Coincidentally, SOX30 is located at the chromosome 5q33 within 5q31-5q35.3 chromosomal region. These data suggest that SOX30 may be a prognostic candidate in ovarian cancer needing further characterization.
In this study, we showed that SOX30 expression was specifically associated with OS of the advanced-stage but not early-stage ovarian cancer patients. The advancedstage patients with different SOX30 expression levels could benefit from different chemotherapy treatments. Next, the functional roles of SOX30 on tumor metastasis were determined in vitro and in vivo, and the molecular mechanism of its function was further explored. At last, the influences of different chemotherapy treatments on tumor cell metastasis and survival time of xenograft nude mice were evaluated in different SOX30 expression cell and mouse models.

\section{Materials and methods}

\section{Cell lines and patient samples}

The human ovarian cancer cell lines Ovcar3 (ATCC No: HTB-161), SKOV3 (ATCC No: HTB-77) and A2780 (ECACC No: 93112519) were purchased from Guangzhou Institute of Biomedicine and Heath (GIBH). GIBH acquired these cells from the American Type Culture Collection (ATCC) or European Collection of Cell Culture (ECACC, Wiltshire, UK) and proceeded to their authentication by STRS analysis. The cell lines H8910 (CBCAS No: TCHu 24) and HEK293 (CBCAS No: GNHu 44) were obtained from the Cell Bank of Chinese Academy of Science (CBCAS, Shanghai, China). CBCAS proceeded to their authentication. The cell lines were cultured in RPMI-1640 (HyClone, Logan, UT, USA)/McCoy's 5A (Invitrogen)/ Dulbecco's Modified Eagle's Medium (DMEM) (HyClone) media supplemented with $10 \%$ fetal bovine serum (FBS, HyClone) and incubated in $5 \% \mathrm{CO}_{2}$ at $37^{\circ} \mathrm{C}$.

A total of 220 patients with cancerous (200 serous and 20 endometrioid), 23 with adjacent non-cancerous and 8 with normal ovarian tissues who underwent surgical resection between 2007 and 2012 were recruited from Daping Hospital or Southwest Hospital Affiliated to Army Medical University in Chongqing, China. The details of patients' information are provided in Supplementary data (see section on supplementary data given at the end of this article). This study was approved by the Ethics Committee of Daping Hospital and Southwest Hospital, and all experiments were performed in accordance with approved guidelines of Army Medical University. Informed consent was signed by all the recruited patients.

\section{Total RNA and protein extraction}

Details are provided in Supplementary data. 


\section{Analysis of gene expression by RT-PCR and RT-qPCR}

Gene expression was determined using RT-PCR. A series of PCRs with different cycles were performed, and the appropriate cycles were chosen. $\beta$-actin was amplified as an internal control. Real-time quantitative PCR (RT-qPCR) was tested by iQ5 real-time detection system (Bio-Rad Laboratories) using GoTaq qPCR Master Mix (Promega). The relative gene expression was calculated by the equation $2^{-\triangle \Delta C T}$. All RT-qPCRs were performed in triplicate. The primers are provided in Supplementary data.

\section{Tissue microarray generation}

The tissue microarray (TMA) containing 220 cancerous and 23 adjacent non-cancerous ovarian tissues were constructed as in the previous study (Gao et al. 2007). To construct TMA slides, two cores within a distance of $30 \mathrm{~mm}$ were taken from each sample as the cancerous tissue and adjacent non-cancerous tissue, and the adjacent non-cancerous tissues were defined by comparing with normal tissue after staining with hematoxylin-eosin and histologically reviewed by two independent pathologists.

\section{Immunohistochemical analysis}

Immunohistochemistry (IHC) was performed as described previously (Han et al. 2014). The primary antibodies were SOX30 antibody (1:300; Abcam, ab26024), E-CADHERIN (1:200; Santa Cruz Biotechnology; sc-71008), N-CADHERIN (1:200; Santa Cruz Biotechnology; sc-59987), FIBRONECTIN/FN1 (1:150, Bioss, bs-0666R) and VIM antibody (1:200; Santa Cruz Biotechnology; sc-53464). The IHC staining was quantified as described in Supplementary data. SOX30 expression was categorized as high and low groups using the mean score combined with median.

\section{Construction of vectors and stable transfected cells}

The expression plasmid was constructed as previously described (Han et al. 2015a). The interference plasmids and luciferase plasmids were constructed as described in Supplementary data. The transfection was performed and stable transfected cells were selected as described in Supplementary data.

\section{Western blotting analysis}

Western blotting (WB) analysis was performed as in the previous study (Han et al. 2015a). Details are provided in Supplementary data.

(c) 2019 Society for Endocrinology Published by Bioscientifica Ltd. Printed in Great Britain

\section{Transwell assay}

Tumor cell migration and invasion were measured by transwell assays in 24-well plates $(8 \mu \mathrm{m}$, Corning, Acton, MA, USA) without or with matrigel (BD Bioscience, San Jose, CA, USA). The Ovcar3, A2780 and SKOV3 cells stably transfected with SOX30 or control vector, or Ovcar3- and SKOV3-SOX30 cells stably transfected with miRNA or negative control plasmids, were suspended at $5 \times 10^{4}$ cells/well in a serum-free medium and seeded in the upper well of the chamber. The lower well of the chamber contained media supplemented with $10 \%$ FBS. The cells that migrated to the lower chamber after $12 \mathrm{~h}$ for migration (without matrigel) or $16 \mathrm{~h}$ for invasion (with matrigel) were stained with $0.1 \%$ crystal violet and counted under a microscope. All experiments were performed in triplicate and repeated thrice.

\section{Chemotherapy treatment assay in vitro}

Ovcar3 stably transfected with SOX30 (Ovcar3-SOX30) or control vector (Ovcar3-vector) cells were suspended at $5 \times 10^{4}$ cells/well in a serum-free medium and seeded in the upper well of the chamber (24-well plates, $8 \mu \mathrm{m}$, Corning) with $3 \mu \mathrm{g} / \mathrm{mL}$ of oxaliplatin (Hengrui Medicine, Lianyungang, Jiangsu Province, China) or $45 \mu \mathrm{g} / \mathrm{mL}$ gemcitabine (Eli Lilly and Company). The lower well of the chamber contained media supplemented with $10 \%$ FBS also with $3 \mu \mathrm{g} / \mathrm{mL}$ of oxaliplatin or $45 \mu \mathrm{g} / \mathrm{mL}$ gemcitabine. The cells that migrated to the lower chamber after $12 \mathrm{~h}$ for migration or $16 \mathrm{~h}$ for invasion were stained with $0.1 \%$ crystal violet and were counted under a microscope.

\section{Metastasis assay in nude mice}

Ovcar3-SOX30 and Ovcar3-vector cells in PBS were injected into the tail vein $\left(3 \times 10^{6}\right.$ cells/mouse $)$ of 6 -weekold Balb/c nude mice for metastasis assay. The nude mice were killed at 7 weeks after injection, and the metastasis of tumor cells was observed. At the same time, the body weight of these nude mice was also measured. All experiments on these mice were approved by the Institutional Animal Care and Use Committee of Army Medical University, China.

\section{Chemotherapy treatment assay in vivo}

The Ovcar3-vector or Ovcar3-SOX30 cells in PBS were inoculated into the tail vein $\left(3 \times 10^{6}\right.$ cells/mouse $)$ of 
6-week-old Balb/c nude mice. The nude mice were i.p. injected with $5 \mathrm{mg} / \mathrm{kg}$ oxaliplatin or $30 \mathrm{mg} / \mathrm{kg}$ gemcitabine at 6 weeks after inoculation of cells, once a day of oxaliplatin and once every three days of gemcitabine for 3 weeks. The long-term survival of these nude mice' inoculation of cells with different chemotherapy drug treatments was determined.

\section{Luciferase-reporter assay}

The Ovcar3 and HEK293 cells were plated in 24-well plates at $4 \times 10^{4}$ cells per well in triplicate for each condition. After overnight incubation, the cells were transfected with a DNA mix containing pGL3-E-CADHERIN/N-CADHERIN/ FIBRONECTIN/VIM promoter-luciferase, pIRES2-EGFPSOX30 or pIRES2-EGFP-empty and pRL-TK plasmids. Luciferase activities were measured at $32 \mathrm{~h}$ post transfection by fluorescence microplate reader measurement system Varioskan LUX (Thermo Fisher) using a dual-luciferasereporter kit (Promega). Each experiment was performed in triplicate and repeated three times.

\section{Chromatin-immunoprecipitation assay}

A Chromatin-immunoprecipitation (ChIP) assay kit (Cell Signaling Technology, \#9004) was used to analyze the interaction between the protein and DNA according to the manufacturer's protocol. Briefly, $5 \times 10^{6}$ Ovcar3 cells or $4 \times 10^{6}$ HEK293 cells were fixed in $1 \%$ formaldehyde. The fixed cells were digested with micrococcal nuclease and were chromatin immunoprecipitated by specific antibody. Then, chromatin was eluted and DNA was purified. The immunoprecipitated DNA and input DNA were used as templates to amplify the target fragments by RT-PCR analyses. The primers used are provided in Supplementary data.

\section{Statistical analysis}

Statistical analyses were performed using SPSS 18.0 software (SPSS, Inc.). Measurement data were analyzed by Student's $t$ test, and the difference in categorical variables was analyzed by chi-square test or linear-bylinear association. OS was calculated using KaplanMeier method and evaluated using log-rank test. Cox regression was used for multivariate analysis of the prognostic predictors. A Kaplan-Meier survival database that contains survival information of 1581 (2015) ovarian cancer patients and gene expression data from Affymetrix microarrays was used (Gyorffy et al. 2012). The probe set is 207678_s_at and the patients were split by auto select best cutoff. A $P$ value of less than 0.05 was considered statistically significant.

\section{Results}

SOX30 is frequently overexpressed in human ovarian cancer tissues

To investigate SOX30 expression in normal ovarian tissues and cancer tissues, RT-PCR and RT-qPCR were performed. SOX30 expression was clearly higher in cancer tissues $(3.26 \pm 1.62)$ than in normal tissues $(1.28 \pm 1.18)$ $(P<0.0001)$ (Supplementary Fig. 1A). To determine whether SOX30 protein expression was altered, we conducted IHC staining for SOX30 on the TMA containing 220 cancerous and 23 adjacent non-cancerous tissues and used a scoring system to consolidate the results using positive percentage and intensity of staining. SOX30 expression was also significantly higher in cancerous tissues $(7.23 \pm 3.75)$ than in adjacent non-cancerous tissues $(2.65 \pm 2.42)(P<0.0001)$ (Supplementary Fig. 1B). These data show that SOX30 is frequently overexpressed in cancerous tissues compared to that in non-cancerous tissues in ovarian cancer.

\section{SOX30 expression is significantly associated with clinical stage and metastasis of ovarian cancer patients}

Based on the IHC results, the surgical specimens were classified into two groups: SOX30 high group (score $\leq 8$ and $\leq 12$ ) and SOX30 low group (score $<8$ ) according to the mean score (Fig. 1A). After investigating the possible associations between SOX30 expression and clinical parameters of the patients, SOX30 expression was significantly associated with clinical stage $(N=220$, $P=0.002)$ and metastasis $(N=220, P=0.023)$ of the patients (Table 1). The incidence of SOX30 overexpression was $72.97 \%(27 / 37)$ in clinical stage I, 66.00\% (33/50) in stage II, 43.43\% (43/99) in stage III and 38.71\% (12/31) in stage IV patients, respectively (Table 1 ). The incidence of SOX30 overexpression was $55.36 \%(93 / 168)$ in the patients without metastasis and $32.14 \%(9 / 28)$ in the patients with metastasis (Table 1). However, SOX30 expression was not correlated with age, histological type, histological grade, tumor location and tumor size $(P>0.05)$ of the patients (Table 1). Moreover, SOX30 expression decreases in the patients from clinical stage I, II, III to IV or from nonmetastasis to metastasis (Fig. 1B and C). These results reveal that SOX30 expression is significantly associated 
A

Low expression $(<8)$

High expression $(8 \leq$ and $\leq 12)$

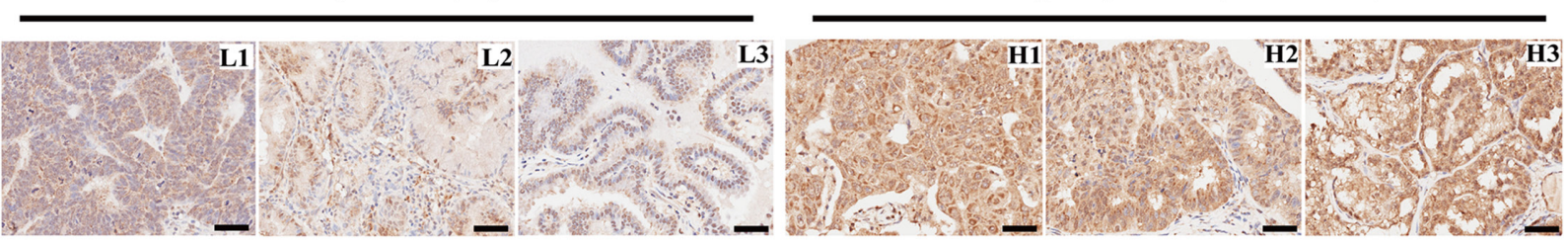

B Stage I
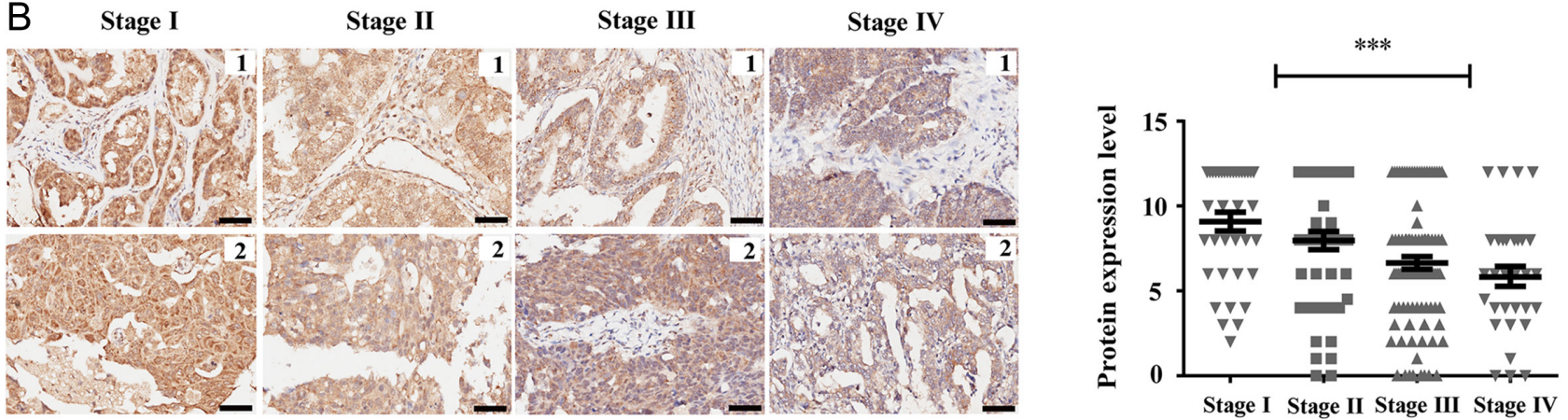

C
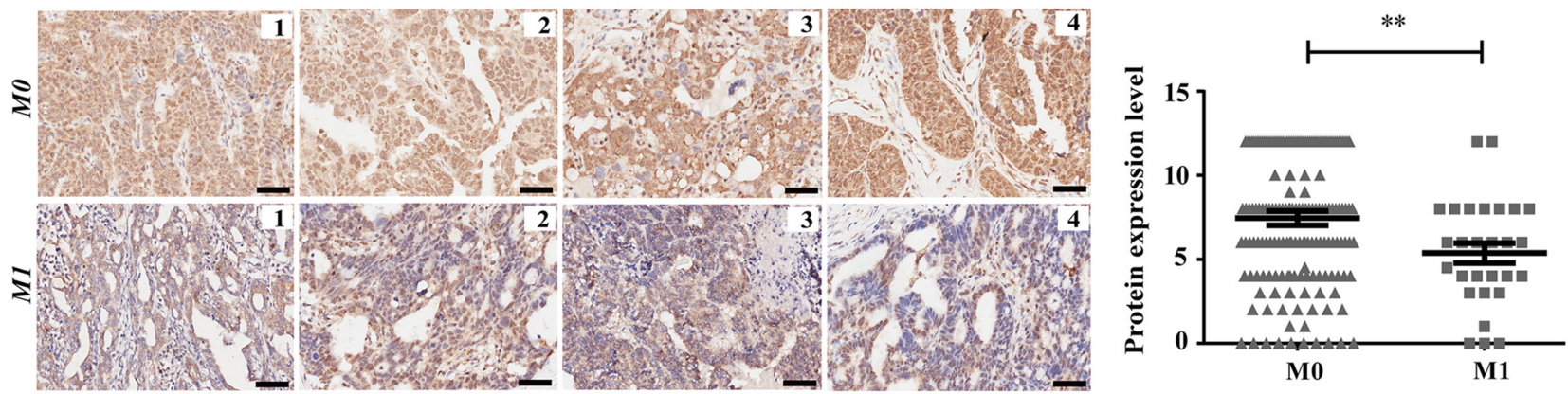

Figure 1

SOX30 expression is associated with clinical stage and metastasis of ovarian cancer patients. (A) Low and high expression levels of SOX30 are shown in tumor ovarian tissues. The expression level of SOX30 is quantified by the score system of positive percentage and intensity of staining. The IHC staining for SOX30 is evaluated and considered positive when immunoreactivity $\geq 5 \%$. Positive percentage of staining is classified into five categories: $<5 \%$ positive cells for 0 score; $5-25 \%$ for 1 score; $26-50 \%$ for 2 score; $51-75 \%$ for 3 score and $\geq 76 \%$ for 4 score. Intensity of staining is graded as negative for 0 score, weak for 1 score, moderate for 2 score and strong for 3 score. The expression level of SOX30 is calculated by the product of category for positive percentage and grade for intensity of staining. SOX30 expression is categorized as high and low group using the mean score. L represents low expression of SOX30 and the score $<8$. $\mathrm{H}$ represents high expression of SOX30 and the score $\leq 8$ and $\leq 12$. Scale bars represent $50 \mu \mathrm{m}$. (B) SOX30 expression is significantly lower in ovarian cancer patients at advanced stage than that at early stage. The $P$ value is measured with Student's $t$-tests. *** represents $P<0.001$. (C) SOX30 expression is significantly lower in ovarian cancer patients with metastasis than that without metastasis. The $P$ value is measured with Student's $t$-tests. M0 represents no-metastatic cancer. M1 represents metastatic cancers. ** represents $P<0.01$.

with clinical stage and metastasis of ovarian cancer patients.

\section{High SOX30 expression uniquely predicts better OS in the ovarian cancer patients diagnosed as advanced stage}

To investigate the correlation between SOX30 expression and survival of the serous ovarian cancer patients, the contribution of SOX30 expression to overall survival (OS) was assessed. Kaplan-Meier analysis indicated that the patients with high SOX30 expression had a better prognosis of OS $(N=200, P=0.001)$, whereas SOX30 expression was not an independent prognostic factor $(P=0.929)$ via Cox regression analysis (Fig. 2A). To confirm this conclusion, we performed the survival analysis of SOX30 expression in these patients split into three groups. The survival data of SOX30 expression in patients split into three groups was consistent with that of SOX30 expression in patients split into two groups (Supplementary Fig. 2). We then analyzed the survival data of the patients at different clinical stages by stratifying these patients according to SOX30 expression. SOX30 expression was not correlated with OS of the patients at early stage (stage I+II) $(N=78$, https://erc.bioscientifica.com

https://doi.org/10.1530/ERC-18-0529 (c) 2019 Society for Endocrinology Published by Bioscientifica Ltd. Printed in Great Britain 
Table 1 Correlations of SOX30 expression with clinicopathologic features in human ovarian cancer patients $(n=220)$.

\begin{tabular}{|c|c|c|c|c|}
\hline \multirow[b]{2}{*}{ Clinical feature } & \multirow[b]{2}{*}{ Total } & \multicolumn{2}{|c|}{ SOX30 expression } & \multirow[b]{2}{*}{$P$ value } \\
\hline & & $\operatorname{High}(n=118)$ & Low $(n=102)$ & \\
\hline \multicolumn{5}{|l|}{ Age (years) } \\
\hline$<52$ & 108 & 52 & 56 & 0.098 \\
\hline$\geq 52$ & 106 & 63 & 43 & \\
\hline \multicolumn{5}{|l|}{ Histological type } \\
\hline Serous & 200 & 107 & 93 & 0.898 \\
\hline Endometrioid & 20 & 11 & 9 & \\
\hline \multicolumn{5}{|l|}{ Histological grade } \\
\hline 1 & 30 & 12 & 18 & 0.183 \\
\hline 2 & 56 & 34 & 22 & \\
\hline 3 & 90 & 47 & 43 & \\
\hline \multicolumn{5}{|l|}{ Clinical stage } \\
\hline I & 37 & 27 & 10 & 0.002 \\
\hline II & 50 & 33 & 17 & \\
\hline III & 96 & 43 & 53 & \\
\hline IV & 31 & 12 & 19 & \\
\hline \multicolumn{5}{|l|}{ Tumor location } \\
\hline Left & 72 & 34 & 38 & 0.217 \\
\hline Right & 91 & 55 & 36 & \\
\hline Both & 57 & 29 & 28 & \\
\hline \multicolumn{5}{|l|}{ Tumor size (cm) } \\
\hline$\leq 10$ & 29 & 15 & 14 & 1.000 \\
\hline$>10$ & 32 & 17 & 15 & \\
\hline \multicolumn{5}{|l|}{ Metastasis } \\
\hline Mo & 168 & 93 & 75 & 0.023 \\
\hline M1 & 28 & 9 & 19 & \\
\hline
\end{tabular}

The $P$ values were measured with Pearson chi-square tests. The tumor clinical stage, tumor status, lymph node status and metastasis were classified according to the international system. All statistical tests are two sided. Bold indicates statistical significance.

$P=0.270$ ) (Fig. 2B). However, SOX30 expression was significantly associated with $\mathrm{OS}(N=122, P<0.0001)$ and was an independent prognostic factor $(N=122, P=0.045$, hazard ratio $(\mathrm{HR})=0.100,95 \%$ confidence interval $(\mathrm{CI})$ 0.010-0.949) for OS of the patients at advanced stage (stage III+IV) (Fig. 2C and Table 2). Using a separate independent set of large samples in clinical microarray KM plotter database (Gyorffy et al. 2012), which collected gene expression data using Affymetrix microarrays and OS information of over 1500 ovarian cancer patients (2015), the un-correlation $(N=1581, P=0.061)$ between SOX30 expression and OS was confirmed in all clinical stage patients (Supplementary Fig. 3A). In consideration of the gene expression data from KM plotter database being different Affymetrix platforms, we analyzed the prognostic significance of SOX30 expression in ovarian cancers from three selected cohorts separately: TCGA dataset, GSE9891 dataset and GSE26712 dataset to verify the reliability of the above result. We also found that SOX3O expression was not associated with the OS of ovarian cancer patients at all clinical stages from TCGA dataset $(N=557, P=0.259)$, GSE9891 $(N=285, P=0.365)$ dataset and GSE26712 dataset $(N=184, P=0.315)$ (Supplementary Fig. 3B, C and D).
Furthermore, using the KM plotter database, SOX30 expression was still not correlated with the OS of the patients at early stage $(N=133, P=0.071)$ (Supplementary Fig. 4). However, there was a statistically significant effect of high SOX30 expression on better OS of the patients at advanced stage $(N=1147, P=0.006, \mathrm{HR}=0.79,95 \% \mathrm{CI}$ $0.66-0.93$ ) (Fig. 2D). These findings suggest that SOX30 expression is a favorable and independent factor for prognosis of ovarian cancer patients at advanced stage.

\section{The advanced-stage patients of different SOX30 expression benefit from different chemotherapies}

To determine whether the association between SOX30 expression and survival of the advanced-stage patients was affected by different chemotherapies, the contributions of chemotherapies on the relationship between SOX30 expression and OS were assessed. From the results, we found a statistically significant effect of high SOX30 expression on better OS of the advanced-stage patients treated with chemotherapy containing platin + taxol (univariate analysis: $N=86, \quad P<0.0001$; multivariate analysis: $N=86, P=0.026$, HR $=0.011,95 \%$ CI $0.000-0.574$ ) c) 2019 Society for Endocrinology Published by Bioscientifica Ltd. Printed in Great Britain 
A

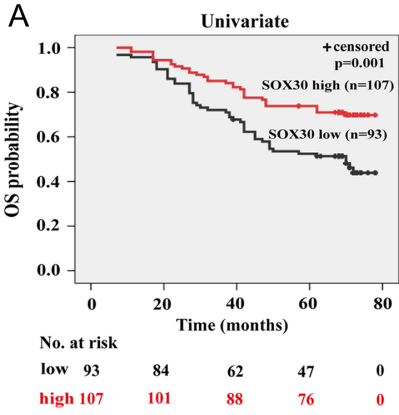

C Stage III+IV Univariate

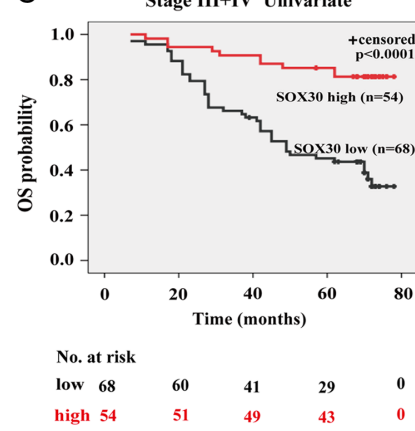

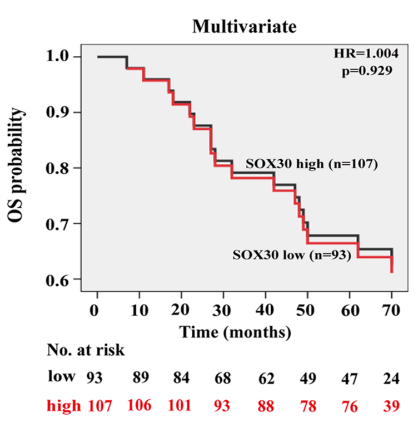

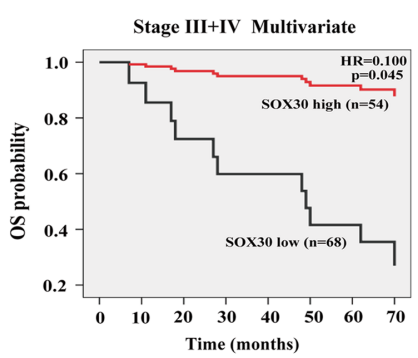

No. at risk

$\begin{array}{lllllllll}\text { low } & 68 & 65 & 60 & 45 & 41 & 30 & 29 & 13\end{array}$ high $\begin{array}{llllllll}54 & 53 & 51 & 50 & 49 & 45 & 43 & 24\end{array}$

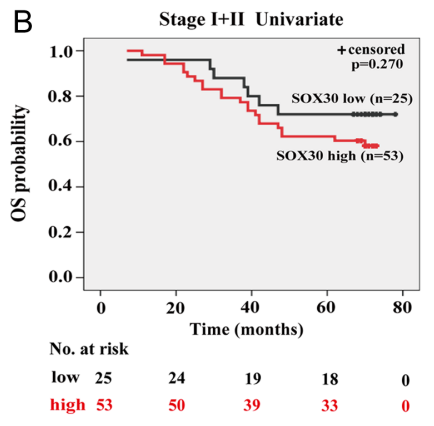

D

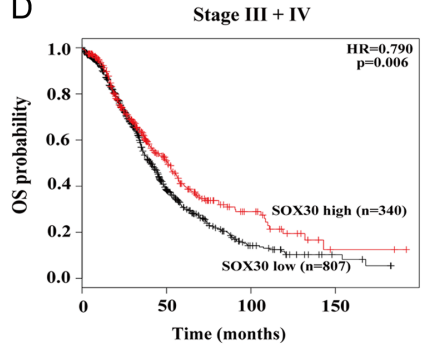

No. at risk

$\begin{array}{llllll}\text { low } & 807 & 168 & 27 & 5\end{array}$

high $340 \quad 96 \quad 23 \quad 2$

\section{Figure 2}

High SOX30 expression is correlated with better overall survival in ovarian cancer patients diagnosed as advanced stage. (A) Survival analysis of SOX30 expression in 200 serous ovarian cancer patients split into two groups. Survival analyses are evaluated by Kaplan-Meier survival curve and multivariate Cox regression. HR represents hazard ratio. (B) Survival analysis of SOX30 expression in 78 serous ovarian cancer patients at early-stage (stage I + II) split into two groups. Survival analyses are evaluated by Kaplan-Meier survival curve. (C) Survival analysis of SOX30 expression in 122 serous ovarian cancer patients at advanced stage (stage III + IV) split into two groups. Survival analyses are evaluated by Kaplan-Meier survival curve and multivariate Cox regression. HR represents hazard ratio. (D) Kaplan-Meir survival analysis of SOX30 expression in 1147 ovarian cancer patients at advanced stage with Kaplan-Meier Plotter (http://kmplot.com/analysis/index). Auto select best cutoff is chosen in the analysis; cutoff value used is 38; expression range of the probe is $1-488$.

(Fig. 3A). Whereas no effect of SOX30 expression was observed on the OS of the advanced-stage patients treated with chemotherapy containing gemcitabine $(P=0.834)$ (Fig. 3B). To further confirm these conclusions, we analyzed the prognostic significance of SOX30 expression in advanced-stage ovarian cancers treated with different chemotherapies in the set of large samples from clinical microarray KM plotter database. There was a statistically significant effect of high SOX30 expression on better OS of the advanced-stage patients treated with chemotherapy containing platin + taxol $(N=664$,
$P=0.025, \mathrm{HR}=0.77,95 \%$ CI $0.61-0.97)$, platin $(N=1026$, $P=0.011, \mathrm{HR}=0.78,95 \%$ CI $0.65-0.95)$ or taxol $(N=681$, $P=0.018, \mathrm{HR}=0.76,95 \%$ CI 0.61-0.96) (Fig. 3C, D and E). In contrary, there was a statistically significant effect of high SOX30 expression on poorer OS of the advancedstage patients treated with chemotherapy containing gemcitabine $(N=129, \quad P=0.049, \quad \mathrm{HR}=1.56, \quad 95 \% \quad \mathrm{CI}$ 1.00-2.45) or topotecan $(N=114, P=0.004, \mathrm{HR}=1.92$, 95\% CI 1.22-3.02) (Fig. 3F and G). These results demonstrate that the advanced-stage patients with high SOX30 expression can receive chemotherapy containing

Table 2 Multivariate analysis of different prognostic factors in 122 advanced-stage (III + IV) serous ovarian cancer patients.

\begin{tabular}{l}
\hline Variable \\
\hline Age (year) \\
Histological grade \\
Tumor size $(\mathrm{cm})$ \\
Tumor location \\
Metastasis \\
SOX30 expression
\end{tabular}

\begin{tabular}{l} 
Comparison \\
\hline $20-73$ \\
Grade 1-3 \\
3-26 \\
Right; left; both \\
M0; M1 \\
High; low \\
\hline
\end{tabular}

\begin{tabular}{c}
\hline HR \\
\hline 0.984 \\
0.750 \\
0.884 \\
1.086 \\
5.655 \\
0.100 \\
\hline
\end{tabular}

\begin{tabular}{cl}
\hline \multicolumn{1}{c}{$\mathbf{9 5 \%} \mathbf{C l}$} \\
\hline $0.928-1.043$ \\
$0.176-3.185$ \\
$0.736-1.061$ \\
$0.420-2.805$ \\
$0.479-66.735$ \\
$0.010-0.949$ \\
\hline
\end{tabular}

\begin{tabular}{c}
\hline P value \\
\hline 0.587 \\
0.696 \\
0.185 \\
0.865 \\
0.169 \\
$\mathbf{0 . 0 4 5}$ \\
\hline
\end{tabular}

$\mathrm{Cl}$, confidence interval; $\mathrm{HR}$, hazard ratio. Bold indicates statistical significance. 

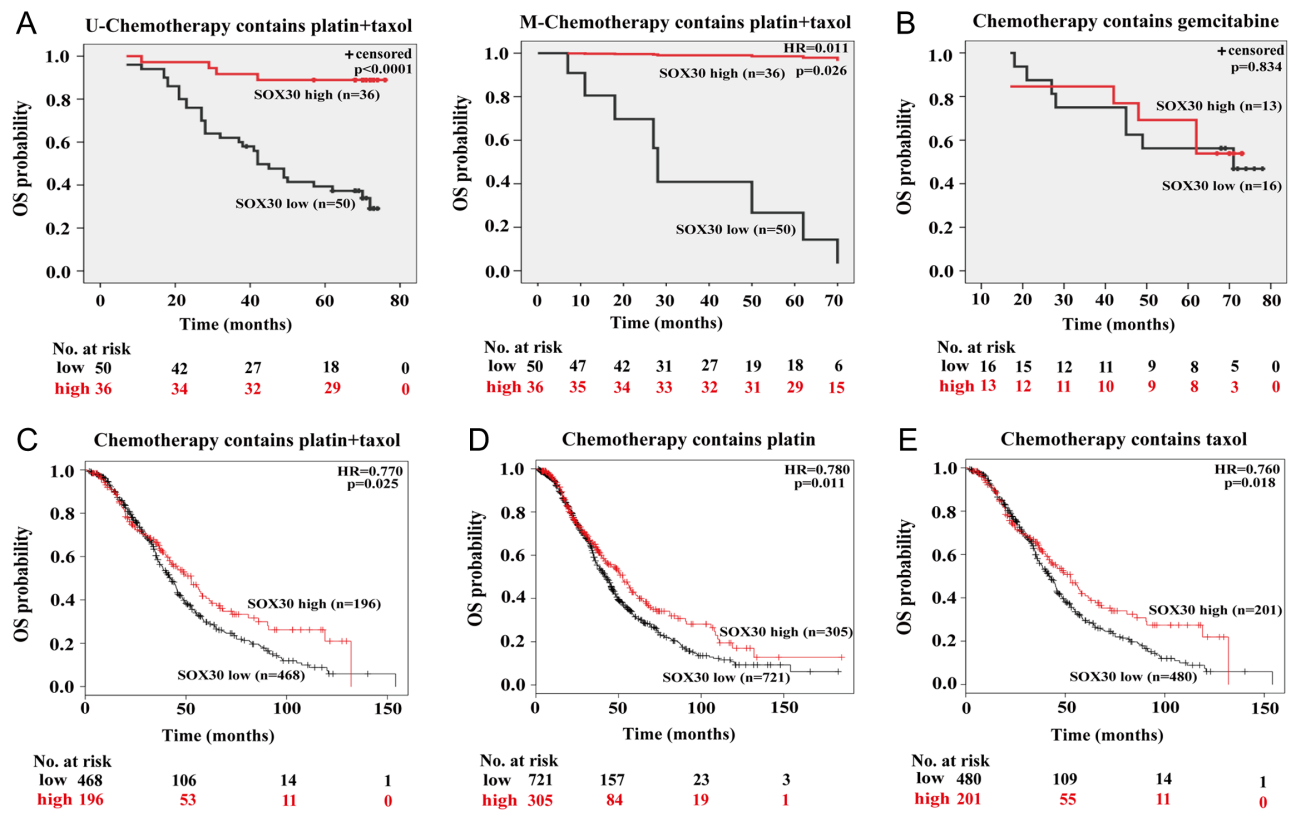

$\begin{array}{llllllll}\text { low } 16 & 15 & 12 & 11 & 9 & 8 & 5 & 0\end{array}$
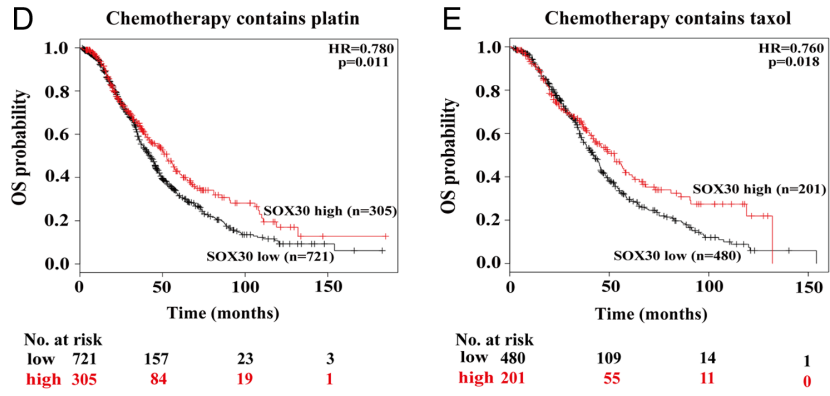

F Chemotherapy contains gemcitabine
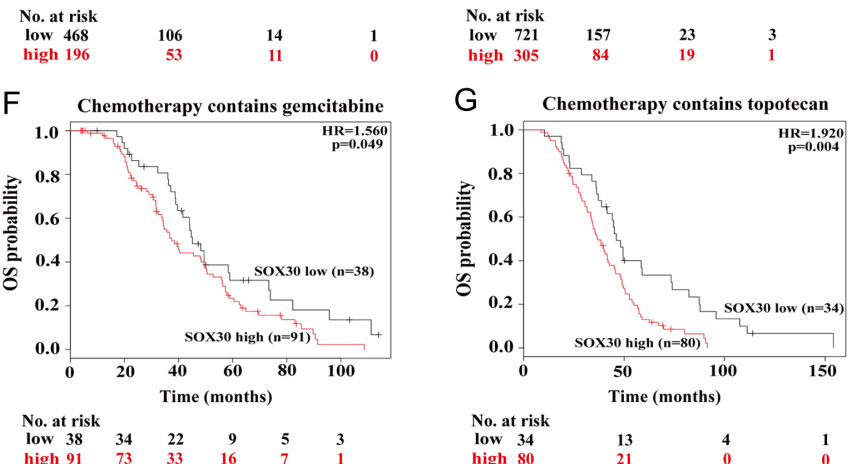
high 201

G

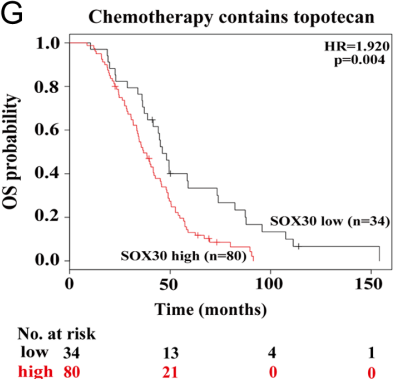

Figure 3

High SOX30 expression suggests different outcomes of advanced-stage ovarian cancer patients with different chemotherapy treatments. (A) Survival analysis of SOX30 expression in 86 advanced-stage serous ovarian cancer patients treated with chemotherapy containing platin + taxol. Survival analyses are evaluated by Kaplan-Meier survival curve and multivariate Cox regression. HR represents hazard ratio. U represents univariate Kaplan-Meier analysis; M represents multivariate Cox regression analysis. (B) Survival analysis of SOX30 expression in 29 advanced-stage serous ovarian cancer patients treated with chemotherapy containing gemcitabine. Survival analysis is evaluated by Kaplan-Meier survival curve. (C) Survival analysis of SOX30 expression in 664 advanced-stage ovarian cancer patients treated with chemotherapy containing platin + taxol. Auto select best cutoff is chosen in the analysis; cutoff value used is 39; expression range of the probe is 1-452. (D) Survival analysis of SOX30 expression in 1026 advanced-stage ovarian cancer patients treated with platin-based chemotherapy. Auto select best cutoff is chosen in the analysis; cutoff value used is 38; expression range of the probe is 1-488. (E) Kaplan-Meir survival analysis of SOX30 expression in 681 advanced-stage ovarian cancer patients treated with chemotherapy containing taxol. Auto select best cutoff is chosen in the analysis; cutoff value used is 39; expression range of the probe is 1-452. (F) Survival analysis of SOX30 expression in 129 advanced-stage ovarian cancer patients treated with chemotherapy containing gemcitabine. Auto select best cutoff is chosen in the analysis; cutoff value used is 7; expression range of the probe is 1-297. (G) Survival analysis of SOX30 expression in 114 advanced-stage ovarian cancer patients treated with chemotherapy containing topotecan. Auto select best cutoff is chosen in the analysis; cutoff value used is 7; expression range of the probe is 1-297.

platin and/or taxol, whereas they do not require chemotherapy containing gemcitabine or topotecan.

\section{SOX30 strongly suppresses ovarian cancer cell migration and invasion}

SOX30 expression was closely associated with clinical stage and metastasis of ovarian cancer patients indicating that SOX30 might be involved in tumor metastasis. To investigate the role of SOX30 on tumor cell migration and invasion, transwell assays without or with matrigel were performed. A significant decrease in migration and invasion ability of cancer cells was observed in SOX30transfected cells compared with empty vector-transfected cells in SOX30 low expression cell lines Ovcar3, A2780 and SKOV3 (Fig. 4A, B, C and Supplementary Fig. 5A, B, C). To further confirm the roles of SOX30, the effect of SOX30 knockdown on cell migration and invasion with miRNA in SOX30-stable transfectants (Ovcar3-SOX30 and SKOV3-SOX30 cells, as none of these tumor cell https://erc.bioscientifica.com

https://doi.org/10.1530/ERC-18-0529 (c) 2019 Society for Endocrinology Published by Bioscientifica Ltd. Printed in Great Britain 
lines was found to highly express SOX30 originally) was investigated. Knockdown of SOX30 significantly increased tumor cell migration and invasion compared with the negative control in Ovcar3-SOX30 and SKOV3-SOX30 cells (Fig. 4D, E, F and Supplementary Fig. 5D, E). These data suggest that SOX30 strongly suppresses tumor cell migration and invasion.

\section{SOX30 impedes tumor cell metastasis in nude mice}

To investigate whether SOX30 suppressed tumor metastasis in vivo, we used a xenograft tumor model to assess the metastasis of Ovcar3-SOX30 cells in nude mice. The body weight of nude mice inoculation of Ovcar3vector cells was sharply decreased compared to that of Ovcar3-SOX30 cells (Fig. 5A), suggesting more tumor metastasis in nude mice inoculation of Ovcar3-vector cells. Further metastatic analyses by tissue observation revealed that the nude mice in Ovcar3-SOX30 group demonstrated a significant decrease of lung metastatic tumors compared with that in Ovcar3-vector group, which was further proved by determining human-specific GAPDH levels to quantify metastatic human cells and hematoxylin and eosin (HE) staining to determine the metastatic tumors (Fig. 5B, C, D, E and F). These results reveal that SOX30 strongly impedes tumor metastasis in vivo.

\section{SOX30 regulates multiple key markers of epithelial-mesenchymal transition}

To gain insight into the possible molecular basis underlying the metastasis suppressive role of SOX30,
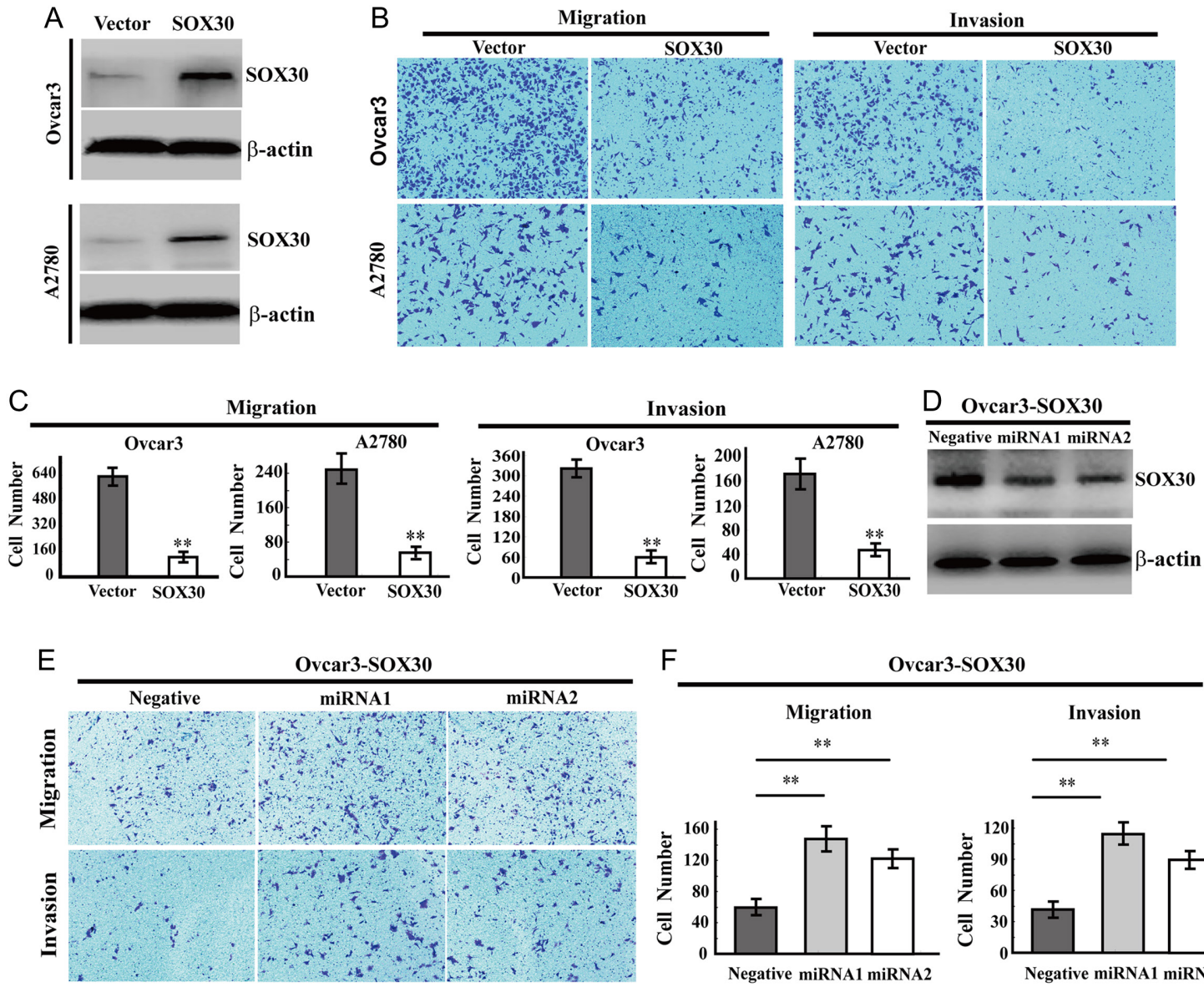

$\mathrm{F}$
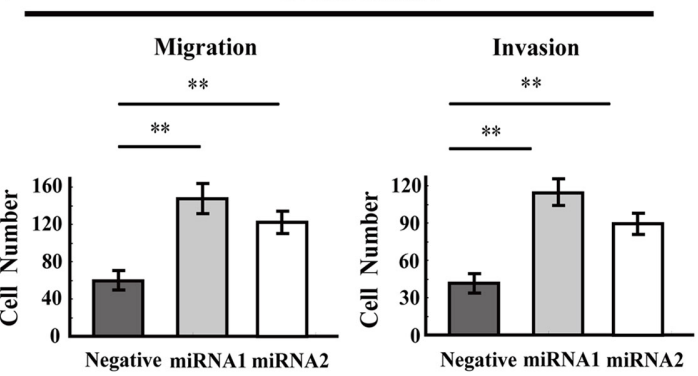

\section{Figure 4}

SOX30 suppresses cancer cell migration and invasion. (A) Transfectants of SOX30 and vector are identified by WB in human ovarian cancer cell lines, A2780 and Ovcar3. (B and C) The migrated or invaded cells are analyzed by transwell assays without or with matrigel in stable SOX30 or vector A2780 and Ovcar3 cells. The migrated or invaded cells in the lower chamber are fixed, stained and determined by the average count of five random microscopic fields. Error bars indicate s.E.M. The $P$ value is measured with Student's $t$-tests. ** represents $P<0.01$. (D) Knockdown expression of SOX30 is identified by WB in Ovcar3-SOX30 stable cells transfected with miRNAs or a negative control. $\beta$-actin is used as an internal control. (E and F) Migration and invasion analyses of the migrated or invaded cells are measured by transwell assays without or with matrigel in stable Ovcar3-SOX30 cells transfected with miRNAs or a negative control. Error bars indicate s.E.M. The $P$ value is measured with Student's $t$-tests. ** represents $P<0.01$. 
we determined the relationship between expression of SOX30 and clinical indicators including P53, ER, PR, CK7, PTEN, CA125, CEA, VIM (VIMENTIN), E-CADHERIN, N-CADHERIN, CDX2 and VILLIN in ovarian cancer samples. A strong negative correlation between SOX30 and N-CADHERIN $(P=0.001)$ or VIM $(P=0.002)$ expression were found (Table 3$)$, whereas a positive correlation between SOX30 and E-CADHERIN $(P=0.013)$ expression was observed (Table 3$)$. To validate these potential targets of SOX30, we determined the expression of these genes in SOX30 overexpression cell model, human cancer tissues, SOX30-knockdown cell model and the xenograft lung metastastic tumors by RT-qPCR, IHC and WB. The experiment results revealed that SOX30 obviously promoted E-CADHERIN expression and inhibited N-CADHERIN and VIM expression (Fig. 6A, B, C, D and Supplementary Fig. 6A). In addition, SOX30 also inhibited the expression of FIBRONECTIN (Fig. 6A, B and C). As N-CADHERIN, VIM, FIBRONECTIN and E-CADHERIN are the key markers of epithelial-mesenchymal transition (EMT), these data show that SOX30 probably regulates the EMT process.

\section{SOX30 indeed prevents the characteristics of EMT process}

To determine whether SOX30 affected EMT process, we performed the morphological analyses of cancer cells with different SOX30 expression. It seemed to be more spindleshaped cells and less polygonal round cells in Ovcar3vector and SKOV3-vector cells than in Ovcar3-SOX30 and SKOV3-SOX30 cells, which was further confirmed by SOX30-knockdown experiments (Fig. 6E and Supplementary Fig. 6B, C). Correspondingly, the SOX30-expressing Ovcar3 and SKOV3 cells tended to get together, whereas no or low SOX30-expressing Ovcar3 and SKOV3 cells were more dispersed (Fig. 6E and Supplementary Fig. 6B, C). These data indicate that the cancer cells without SOX30 expression are easier to leave the tissue parenchyma and enter the systemic circulations leading to distant metastases.

\section{SOX30 transcriptionally regulates the expression of EMT markers}

Bioinformatics analyses revealed that the promoters of N-CADHERIN, VIM, FIBRONECTIN and E-CADHERIN
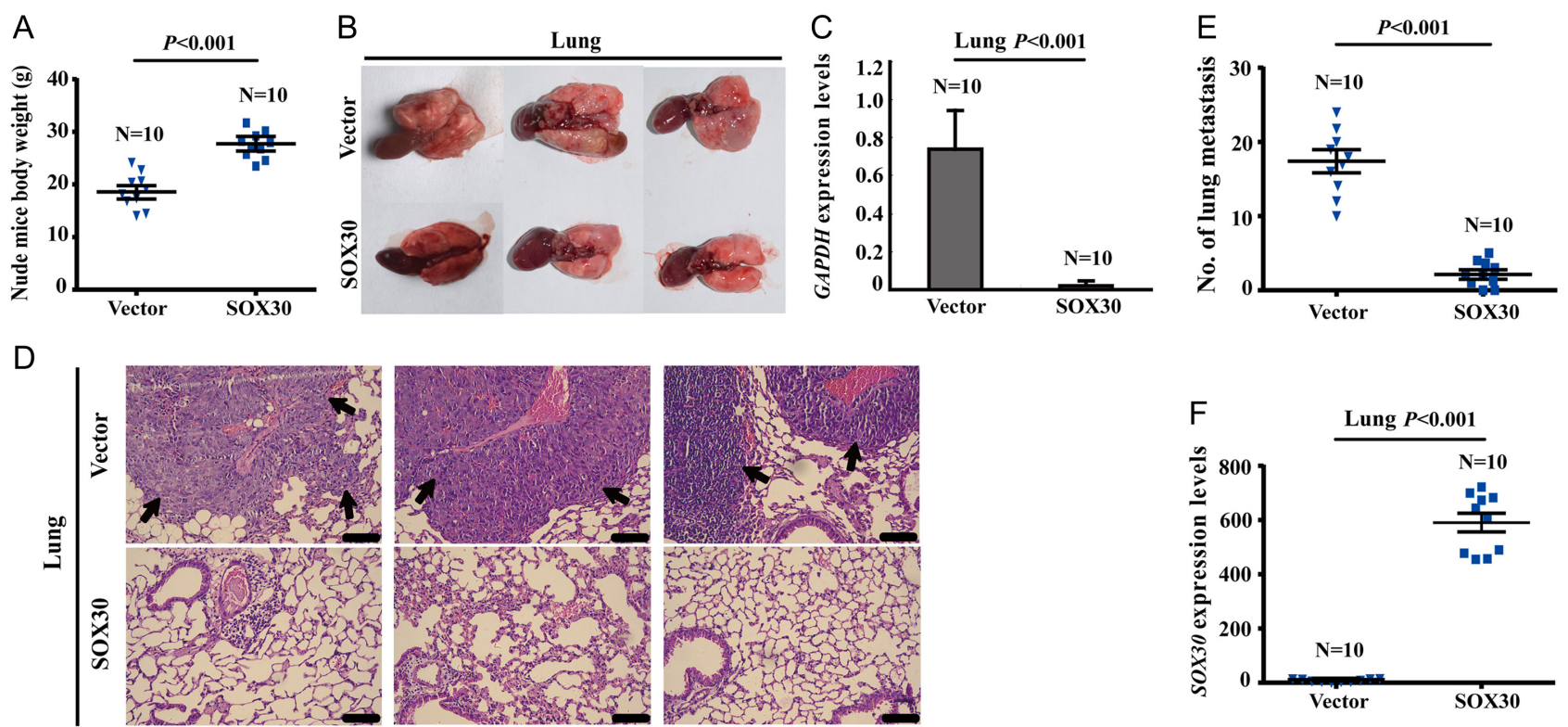

Figure 5

SOX30 strongly impedes tumor metastasis in nude mice. (A) The body weight of nude mice inoculation of vector stable cells $(N=10)$ is sharply decreased compared to that inoculation of SOX30 stable cells $(N=10)$. Error bars indicate s.E.M. The $P$ value is measured with Student's $t$-tests. (B) Lung metastasis of Ovcar3-SOX30 stable cells $(N=10)$ or Ovcar3-vector stable cells in nude mice $(N=10)$ is determined by tissue observation. The images (random selection) provided are representative three of findings from the ten animals. (C) The metastasis of Ovcar3 cells are measured by the expression level of humanspecific GAPDH in lung tissues using RT-qPCR. The expression level of human-specific GAPDH is used to quantify the metastatic human cancer cells. The $P$ value is measured with Student's $t$-tests. ( $D$ and E) Lung metastasis of Ovcar3-SOX30 stable cells or Ovcar3-vector stable cells in nude mice is determined by hematoxylin and eosin (HE) staining. Arrows indicate the metastasis loci. Scale bars represent $50 \mu m$. The images (random selection) of HE staining are representative three of findings from the ten animals. Error bars indicate S.E.M. The $P$ value is measured with Student's $t$-tests. (F) The mRNA expression of SOX30 is examined by RT-qPCR in the xenograft lung metastastic tumors. ACTIN is used as an internal control. 
Table 3 Correlations of SOX30 expression with expression of clinical indicators in human serous ovarian cancer patients $(n=200)$.

\begin{tabular}{|c|c|c|c|c|}
\hline \multirow{2}{*}{$\begin{array}{l}\text { Expression } \\
\text { indicators }\end{array}$} & \multirow[b]{2}{*}{ Total } & \multicolumn{2}{|c|}{ SOX30 expression } & \multirow[b]{2}{*}{$P$ value } \\
\hline & & High $(n=107)$ & Low $(n=93)$ & \\
\hline \multicolumn{5}{|l|}{ P53 } \\
\hline Negative & 24 & 15 & 9 & \multirow[t]{2}{*}{0.583} \\
\hline Positive & 59 & 33 & 26 & \\
\hline \multicolumn{5}{|l|}{ ER } \\
\hline Negative & 36 & 22 & 14 & \multirow[t]{2}{*}{0.561} \\
\hline Positive & 35 & 19 & 16 & \\
\hline \multicolumn{5}{|l|}{ PR } \\
\hline Negative & 54 & 29 & 27 & \multirow[t]{2}{*}{0.071} \\
\hline Positive & 17 & 13 & 4 & \\
\hline \multicolumn{5}{|l|}{ CK7 } \\
\hline Negative & 9 & 7 & 2 & \multirow[t]{2}{*}{0.241} \\
\hline Positive & 56 & 32 & 24 & \\
\hline \multicolumn{5}{|l|}{ PTEN } \\
\hline Negative & 16 & 7 & 9 & \multirow[t]{2}{*}{0.324} \\
\hline Positive & 27 & 16 & 11 & \\
\hline \multicolumn{5}{|l|}{ CA125 } \\
\hline Negative & 17 & 8 & 9 & \multirow[t]{2}{*}{0.216} \\
\hline Positive & 58 & 37 & 21 & \\
\hline \multicolumn{5}{|l|}{ CEA } \\
\hline Negative & 37 & 23 & 14 & \multirow[t]{2}{*}{0.647} \\
\hline Positive & 10 & 7 & 3 & \\
\hline \multicolumn{5}{|l|}{ VIM } \\
\hline Negative & 20 & 17 & 3 & \multirow[t]{2}{*}{0.002} \\
\hline Positive & 15 & 5 & 10 & \\
\hline \multicolumn{5}{|l|}{ E-cadherin } \\
\hline Negative & 27 & 12 & 15 & \multirow[t]{2}{*}{0.013} \\
\hline Positive & 30 & 23 & 7 & \\
\hline \multicolumn{5}{|l|}{$\mathrm{N}$-cadherin } \\
\hline Negative & 30 & 22 & 8 & \multirow[t]{2}{*}{0.001} \\
\hline Positive & 34 & 11 & 23 & \\
\hline \multicolumn{5}{|l|}{ CDX2 } \\
\hline Negative & 14 & 8 & 6 & \multirow[t]{2}{*}{0.806} \\
\hline Positive & 8 & 5 & 3 & \\
\hline \multicolumn{5}{|l|}{ Villin } \\
\hline Negative & 8 & 5 & 3 & \multirow[t]{2}{*}{0.636} \\
\hline Positive & 11 & 8 & 3 & \\
\hline
\end{tabular}

The $P$ values were measured with Pearson chi-square tests. All statistical tests are two sided. Bold indicates statistical significance.

contained consensus binding sites of SOX30 (Supplementary Fig. 7). Luciferase-reporter assays indicated that SOX30 overexpression significantly attenuated the promoter activities of $N$-CADHERIN ( $-1700 \mathrm{bp}$ to $194 \mathrm{bp}$ ), VIM ( $-1456 \mathrm{bp}$ to $+174 \mathrm{bp})$ and FIBRONECTIN (-1668 bp to $279 \mathrm{bp}$ ), whereas SOX30 overexpression significantly activated the promoter activity of E-CADHERIN (-1698 bp to 56bp) (Fig. 7A). To further determine whether SOX30 regulated N-CADHERIN, VIM, FIBRONECTIN and E-CADHERIN by direct binding to promoters, the ChIP-PCR assays were performed. As there were only a few potential binding sites of SOX30 in N-CADHERIN, VIM, FIBRONECTIN and E-CADHERIN promoters, we designed pairs of primers according to the potential binding sites and performed the ChIP-PCR assay using SOX30-specific antibody in the HEK293 and Ovcar3 cell lines. The ChIP-PCR data demonstrated that a direct binding of SOX30 to promoters of N-CADHERIN, FIBRONECTIN and E-CADHERIN (it seemed a faint band in SOX30-transfected cells of N-cadherin promoter) was found, whereas SOX30 regulated VIM not by directly binding to its promoter (Fig. 7B). These data suggest that SOX30 transcriptionally regulates the expression of these EMT markers directly or indirectly.

\section{EMT process is required for the anti-metastatic role of SOX30}

To analyze whether EMT process was required for the anti-metastatic role of SOX30, we downregulated E-cadherin expression and/or upregulated N-cadherin expression enforcedly when SOX30 was overexpressed and examined the metastasis of tumor cells. The antimetastatic role of SOX30 was significantly diminished after silencing E-cadherin by its siRNA or strengthening $\mathrm{N}$-cadherin by its expression vector during overexpression of SOX30 (Fig. 7C and D). Moreover, the anti-metastatic role of SOX30 was also strongly diminished after silencing E-cadherin and strengthening $\mathrm{N}$-cadherin during overexpression of SOX30 (Fig. 7C and D). These data indicate that EMT process is indeed required for SOX30 as a tumor metastasis suppressor.

\section{Different chemotherapies combined with SOX30 expression influence cancer cell migration and invasion differently that is associated with EMT}

The advanced-stage patients with different SOX30 expressions benefit from different chemotherapy treatments. To further determine the possible cause of the different benefits, we analyzed whether the chemotherapies combined with SOX30 overexpression contributed to tumor cell metastasis. Oxaliplatin treatment $(3 \mu \mathrm{g} / \mathrm{mL})$ combined with overexpression of SOX30 seemed to enhance the suppression of cancer cell metastasis (Fig. 8A). However, gemcitabine treatment $(45 \mu \mathrm{g} / \mathrm{mL})$ combined with overexpression of SOX30 seemed to jointly increase the metastasis ability of cancer cells (Fig. 8B). To further determine whether the different effects on cancer cell metastasis of chemotherapy drugs were associated with SOX30 and EMT, we evaluated the expression of SOX30 and EMT markers in the different cancer cells treated with chemotherapy drugs. 

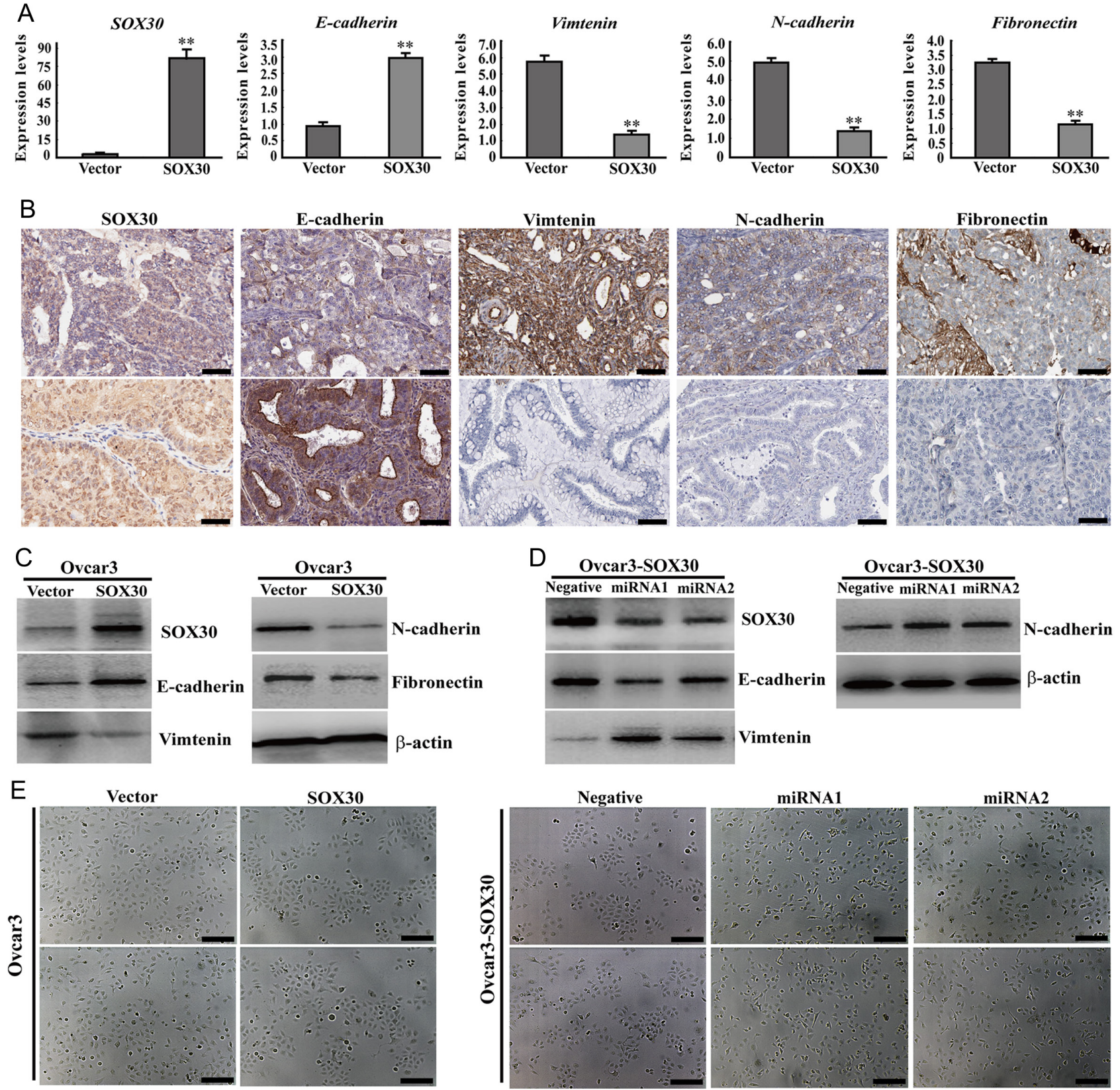

Figure 6

SOX30 regulates multiple key markers of EMT and prevents EMT. (A) Ectopic expression of SOX30 significantly promotes endogenous E-cadherin expression and suppresses the endogenous N-cadherin, VIM and Fibronectin expression by RT-qPCR. $\beta$-Actin is used as an internal control. Error bars indicate s.E.M. The $P$ value is measured with Student's $t$-tests. ** represents $P<0.01$. (B) The endogenous protein expressions of SOX30, E-cadherin, $\mathrm{N}$-cadherin, VIM and fibronectin are determined by IHC in human ovarian cancer samples. Scale bars represent $50 \mu \mathrm{m}$. (C) Ectopic expression of SOX30 promotes endogenous E-cadherin expression and suppresses the endogenous $\mathrm{N}$-cadherin, VIM and fibronectin expression by WB. $\beta$-Actin is used as an internal control. (D) Knockdown SOX30 expression suppresses E-cadherin expression and promotes $\mathrm{N}$-cadherin and VIM expression by WB. $\beta$-Actin is used as an internal control. (E) Morphological analyses of cancer cells with different SOX30 expression are performed to determine characteristics of EMT. Scale bars represent $100 \mu \mathrm{m}$.

The EMT markers, N-CADHERIN, VIM, FIBRONECTIN and E-CADHERIN were significantly regulated, whereas SOX30 expression was not affected by the chemotherapy drugs (Fig. 8C and Supplementary Fig. 8). These data reveal that different chemotherapy drugs combined with overexpression of SOX30 influence cancer cell migration and invasion differently, which is associated with the EMT process. (c) 2019 Society for Endocrinology Published by Bioscientifica Ltd. Printed in Great Britain 
A
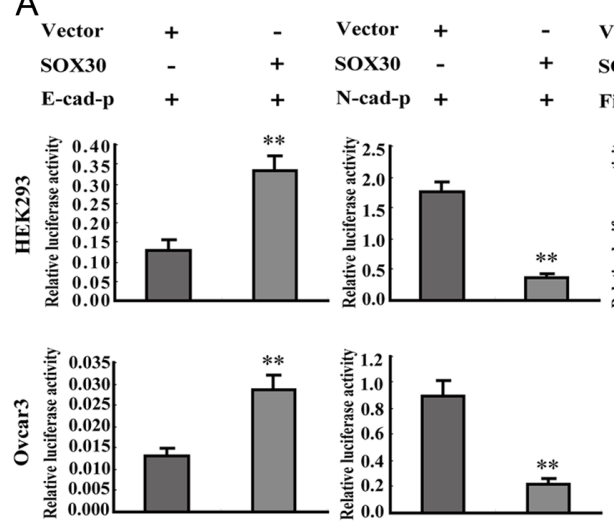

C

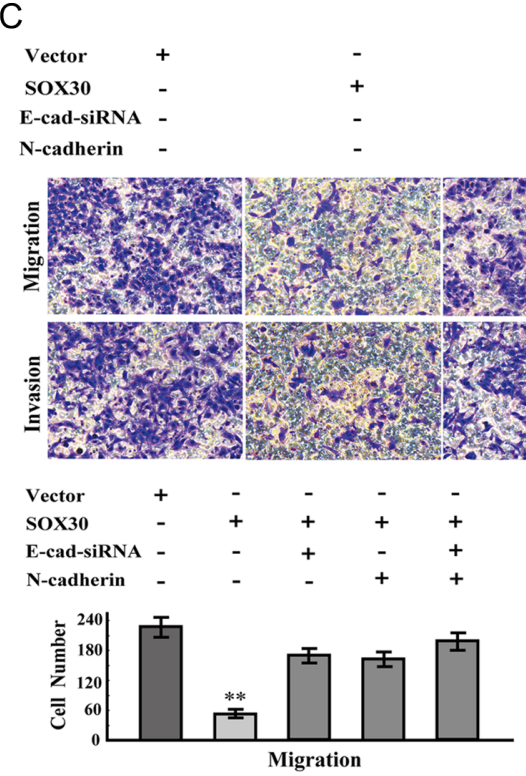

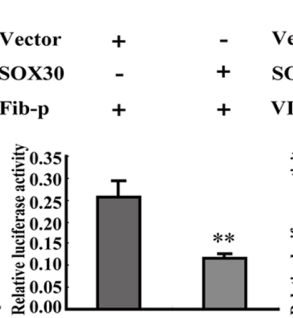

Vector
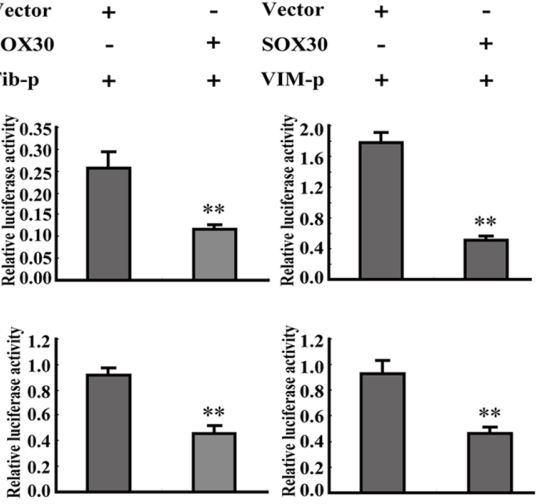

B

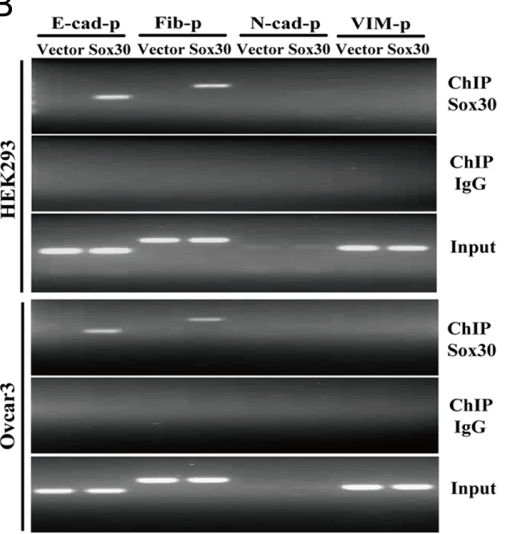

\section{$\mathrm{D}$}
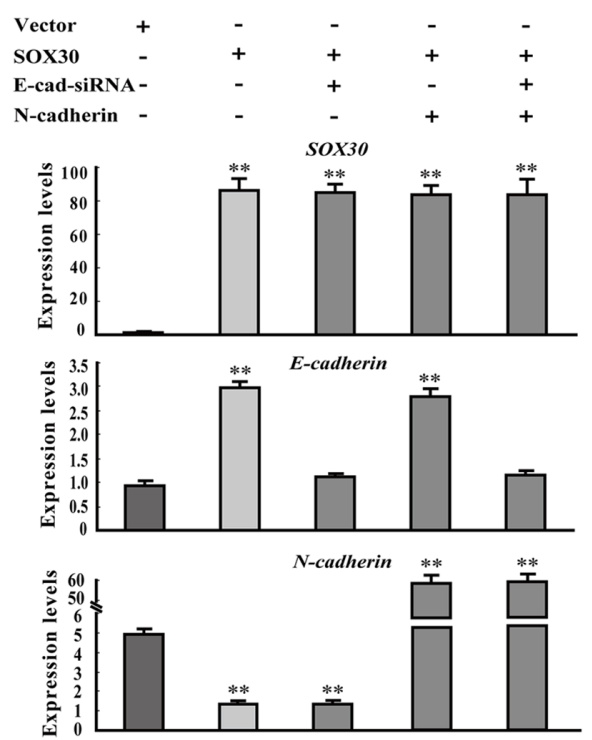

Figure 7

SOX30 transcriptionally regulates the expression of EMT markers. (A) SOX30 regulates the promoter activities and their transcriptions of E-cadherin, $\mathrm{N}$-cadherin, VIM and Fibronectin as detected by luciferase-reporter assays. The luciferase-reporter linked with full-length native promoters of E-cadherin (E-cad-p), N-cadherin (N-cad-p), VIM (VIM-p) and fibronectin (Fib-p) are used for the luciferase-reporter assays in Ovcar3 and HEK293 cells. The results normalized with controls are presented as averages with S.E.M. The $P$ value is measured with Student's $t$-tests. ** represents $P<0.01$. (B) ChIP-PCR is performed to identify the direct binding targets of SOX30. SOX30 regulates E-cadherin, Fibronectin and $N$-cadherin by direct binding to their promoters, whereas SOX30 regulates VIM not by direct binding to its promoter. E-cad-p, Fib-p, N-cad-p and VIM-p represent the promoters of E-cadherin, fibronectin, $\mathrm{N}$-cadherin and VIM, respectively. (C) Analysis of cell migration and invasion in Ovcar3 cells transfected with empty vector, sOX30, co-transfected with SOX30 and N-cadherin, co-transfected with SOX30 and E-cadherin siRNA (E-cad siRNA) or co-transfected with SOX30, N-cadherin and E-cadherin siRNA (E-cad siRNA). The $P$ value is measured with Student's $t$-tests. $* * P<0.01$. (D) The expressions of SOX30, E-cadherin and $N$-cadherin are analyzed by RT-qPCR at $48 \mathrm{~h}$ transfected with empty vector, SOX30, co-transfected with SOX30 and N-cadherin, co-transfected with SOX30 and E-cadherin siRNA (E-cad siRNA) or co-transfected with SOX30, N-cadherin and E-cadherin siRNA (E-cad siRNA) in Ovcar3 cells.

\section{Different chemotherapies combined with SOX30 expression influence the survival of xenograft nude mice differently}

To further confirm whether the chemotherapies combined with SOX30 expression influenced tumor metastasis in vivo, we established a xenograft tumor and determined the long-term survival in the nude mice inoculation of Ovcar3vector cells and Ovcar3-SOX30 cells with treatments using different chemotherapy drugs. Seventy nude mice divided into six groups (vector group $(N=15)$, namely vector+oxaliplatin group $(N=10)$, vector + gemcitabine group $(N=10)$, SOX30 group $(N=15)$, SOX30+oxaliplatin group $(N=10)$ and SOX30+gemcitabine group $(N=10))$, were monitored for survival changes by injection of Ovcar3-SOX30 or Ovcar3-vector cells into the tail vein and treatment with chemotherapy drugs. The nude mice from Ovcar3-SOX30 group had a significantly 
A

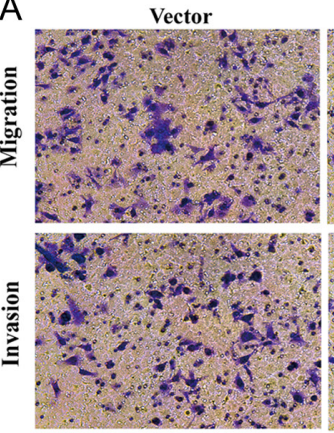

Vector+oxaliplatin

SOX30
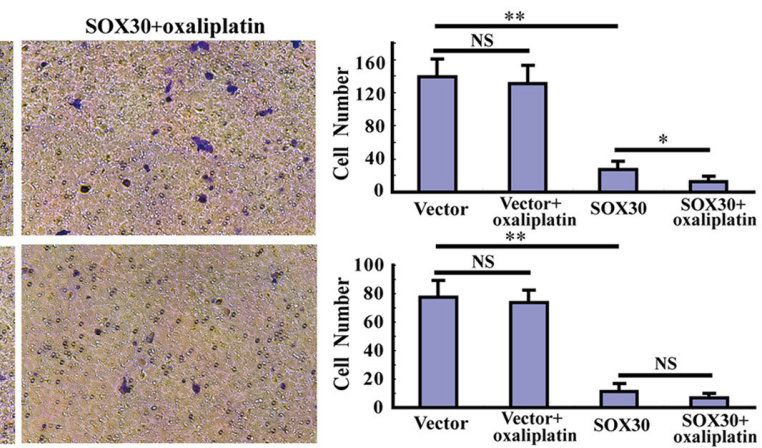

B

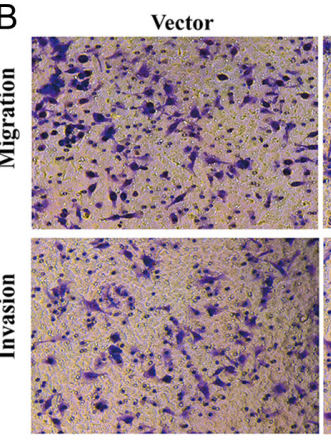

Vector+gemcitabine
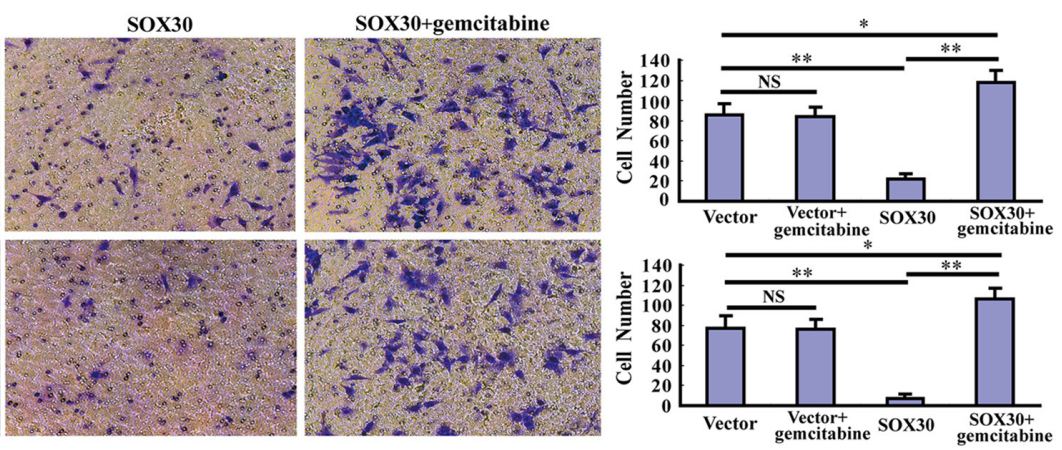

C
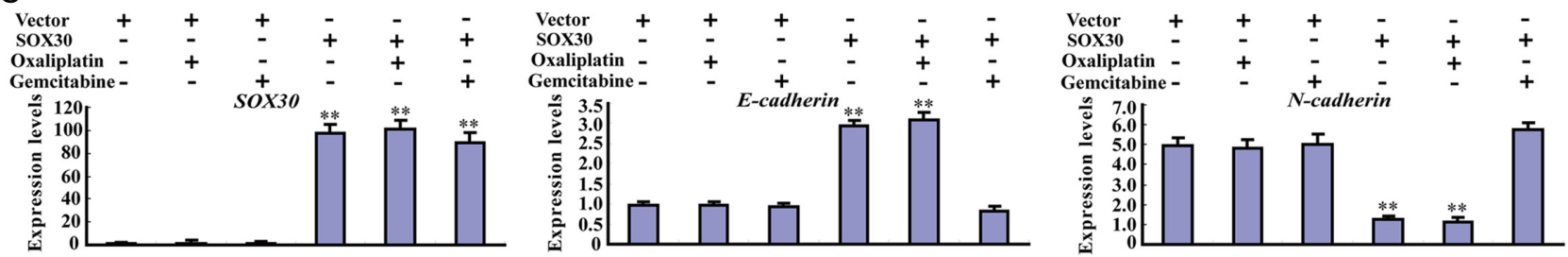

D
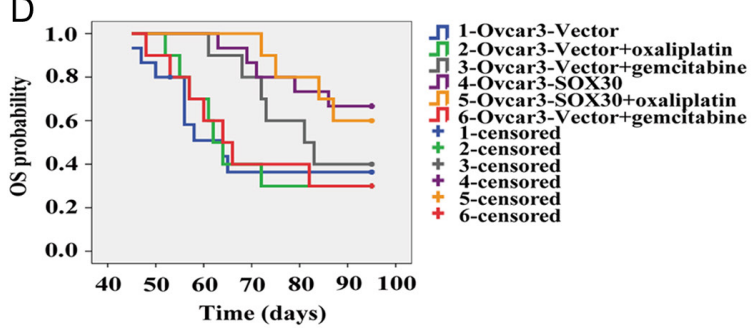

E

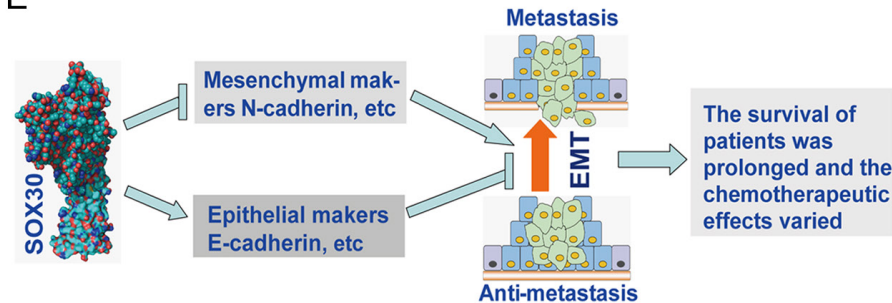

Figure 8

Different chemotherapy treatments combined with SOX30 expression influence tumor cell metastasis differently via EMT. (A) The migrated or invaded cells are analyzed by transwell assays in stable SOX30 or vector Ovcar3 cells treated with $3 \mu \mathrm{g} / \mathrm{mL}$ oxaliplatin. The migrated or invaded cells in the lower chamber are fixed, stained and determined by the average count of five random microscopic fields. Error bars indicate s.E.M. The $P$ value is measured with Student's $t$-tests. * represents $P<0.05$. ** represents $P<0.01$. NS represents non-statistical significance. (B) The migrated or invaded cells are measured by transwell assays in stable SOX30 or vector Ovcar3 cells treated with $45 \mu \mathrm{g} / \mathrm{mL}$ gemcitabine. Error bars indicate S.E.M. The $P$ value is measured with Student's $t$-tests. * represents $P<0.05$. ** represents $P<0.01$. (C) The expressions of $N$-CADHERIN and E-CADHERIN are significantly regulated, whereas SOX30 expression is not affected by chemotherapy drugs. $\beta$-Actin is used as an internal control. Error bars indicate s.E.M. The $P$ value is measured with Student's $t$-tests. ** represents $P<0.01$. (D) Different chemotherapies combined with SOX30 expression influence the survival of xenograft nude mice differently. Survival and statistical significance are determined by Kaplan-Meier curves and log-rank test. (E) A schematic illustration of how SOX30 regulates tumor metastasis that is involved in chemotherapy treatments in ovarian cancer.

prolonged survival time compared with the ones from Ovcar3-vector group ( $P=0.030$, Fig. 8D). Approximately $66.67 \%(10 / 15)$ of the nude mice from Ovcar3-SOX30 group still lived at 95 days after cell injection, whereas only $40.00 \%(6 / 15)$ of the nude mice from Ovcar3- vector group survived at that time point (Supplementary Table 1). The survival time of the nude mice from Ovcar3vector group was not significantly affected by oxaliplatin treatment (vector+oxaliplatin group, $P=0.990$, Fig. 8D) or gemcitabine treatment (vector+gemcitabine group, 
$P=0.322$, Fig. $8 \mathrm{D})$. The survival time of the nude mice from Ovcar3-SOX30 group was still not significantly affected by oxaliplatin treatment (SOX30+oxaliplatin group, $P=0.869$, Fig. $8 \mathrm{D}$ ), whereas it was significantly affected by gemcitabine treatment (SOX30+gemcitabine group, $P=0.024$, Fig. $8 D)$. About $66.67 \%(10 / 15)$ of the nude mice from Ovcar3-SOX30 group lived for 95 days after cell injection, whereas only $30.00 \%(3 / 10)$ of the nude mice treated with gemcitabine from Ovcar3-SOX30 group survived at that time (Supplementary Table 1). These results demonstrate that chemotherapies combined with SOX30 expression indeed influence the survival time of xenograft nude mice differently.

\section{Discussion}

The amplification in the chromosomal region 5q31-5q35.3 exhibits the strongest correlation with the OS of advanced-stage ovarian cancers (Birrer et al. 2007, Wei et al. 2013). SOX30 has been recently identified as a key player in several types of tumors (Han et al. 2015a, 2018, Guo et al. 2017, Liu et al. 2018) and a potential prognostic marker in lung cancer, bladder cancer and myeloid malignancies (Han et al. 2015b, Liu et al. 2018, Zhou et al. 2018). Interestingly, SOX30 is located at chromosome 5q33 within 5q31-5q35.3 chromosomal region suggesting a potential prognostic value of SOX30 in advanced-stage ovarian cancers. In the present study, SOX30 expression is indeed not correlated with OS of early-stage patients; however, it is significantly associated with OS of the patients at advanced stage. These data reveals that SOX30 may be a strong prognostic marker for advanced-stage ovarian cancers.

Currently, the standard treatment for ovarian cancer patients are still surgical resection and systemic chemotherapy (Kartalou \& Essigmann 2001, Marsh 2009). Systemic chemotherapy seems to have got an increasingly important role on the effective treatment of advancedstage ovarian cancer. Although chemotherapy improves survival of the patients, the true challenge is to determine which of these patients would most benefit from specific chemotherapy and are at a higher risk (Lorusso \& Pignata 2017, Oseledchyk et al. 2017). Thus, identification of sensitive respond markers for chemotherapy is greatly important to select patients who benefit from a specific chemotherapy. In the present study, to determine whether SOX30 expression in resection specimens could be incorporated into chemotherapeutic treatment for the advanced-stage ovarian cancer patients, we analyzed the survival data of the patients with different chemotherapies by stratifying the patients according to SOX30 expression. A statistically significant effect of high SOX30 expression on better OS is observed in the advanced-stage patients treated with platin and/or taxol-based chemotherapy, revealing that the advanced-stage patients with high SOX30 expression are more likely to derive long-term benefit and can receive chemotherapy containing platin and/or taxol. In contrast, there is no effect of SOX30 expression on OS or a statistically significant effect of high SOX30 expression on poorer OS of the advancedstage ovarian cancer patients treated with chemotherapy containing gemcitabine or topotecan, indicating that the advanced-stage patients with high SOX30 expression do not require chemotherapy containing gemcitabine or topotecan. The conclusions are further confirmed by the survival data of xenograft nude mice treated with chemotherapies combined with different SOX30 expression. Our data provide evidence that SOX30 expression can be incorporated into chemotherapeutic treatment for advanced-stage ovarian cancer patients. However, a prospective study of large samples should be performed to determine the effectiveness of clinical applications for chemotherapeutic treatment based on SOX30 expression as soon as possible. In addition, given the diversity of ovarian cancer subtypes, we would like to know whether this phenomenon is universal for all subtypes of ovarian cancer or just for one or some subtypes of ovarian cancer in a future larger cohort.

Previous study has shown that SOX30 is expressed in adjacent non-cancerous and normal lung tissues but is downregulated in cancerous tissues (Han et al. 2015a), and functional studies reveal SOX30 as a tumor suppressor via promoting tumor cell apoptosis or inhibiting tumor cell metastasis (Han et al. 2015a, 2018). In this study, we find that SOX30 is silenced or downregulated in normal or adjacent non-cancerous ovarian tissues but is frequently overexpressed in cancerous tissues, which is contrary to the expression pattern of SOX30 in lung cancer. Does this expression data suggest that SOX30 is an oncogene in ovarian cancer? To explore the role of SOX30 in ovarian cancer, we generated different gain-of-function models. SOX30 strongly impedes tumor cell metastasis in vitro and in vivo. These results reveal that SOX30 still acts as a tumor suppressor in ovarian cancer as well as in lung cancer.

In line with the associations between SOX30 and survival of the advanced-stage patients treated with different chemotherapies, oxaliplatin and SOX30 seem to co-enhance the suppression of cancer cell metastasis, whereas the combined effect of gemcitabine and SOX30 significantly promote cancer cell metastasis. These results 
suggest that tumor cell metastasis is more inhibited in the advanced-stage patients with high SOX30 expression when treated with oxaliplatin and the survival of these patients is prolonged, whereas tumor cell metastasis is increased in the advanced-stage patients with high SOX30 expression when treated with gemcitabine and the survival of these patients is shortened. However, the molecular mechanisms behind oxaliplatin and SOX30 co-inhibition or gemcitabine and SOX30 joint enhancement of tumor metastasis are still unknown. To gain insight into this issue, we try to explore the possible molecular basis and find that the different influences on tumor metastasis of chemotherapies combined with SOX30 expression are associated with the EMT process.

EMT is a process that turns epithelial cells into mesenchymal cells. During this process, the epithelial cells will lose cell-cell junctions and apical-basal polarity, reorganize cytoskeletal architecture, re-define cell shape, re-program expression of key genes and finally increases the motility and invasive phenotype of cells (Thiery \& Sleeman 2006, Thiery et al. 2009). Recent studies have demonstrated that EMT is exploited by tumor cells to facilitate escape from the primary tumor and has been considered as a key regulator of tumor metastasis in multiple types of cancers (Davis et al. 2014, Nieto et al. 2016). Therefore, EMT has been a potential therapeutic target for many kinds of cancers. However, the molecular mechanism of EMT in tumor metastasis is still largely unexplored. Previous studies have shown that the EMT is characterized by loss of E-cadherin and gain of $\mathrm{N}$-cadherin (Acloque et al. 2009, Yilmaz \& Christofori 2009, Ye \& Weinberg 2015). In our present study, SOX30 has been suggested as a new metastasis suppressor in ovarian cancer with upregulation of E-CADHERIN and downregulation of N-CADHERIN, VIM and FIBRONECTIN, indicating that SOX30 inhibits tumor metastasis via preventing EMT in ovarian cancer. Moreover, SOX30 prevents the EMT process by transcriptional regulation of the key markers of EMT directly or indirectly. These data show that SOX30 is a novel key inhibitor of EMT.

In conclusion, SOX30 inhibits tumor metastasis via preventing EMT process and is a unique potential marker of prognostic evaluation that can be incorporated into chemotherapeutic treatment of advanced-stage ovarian cancer patients (Fig. 8E).

\section{Supplementary data}

This is linked to the online version of the paper at https://doi.org/10.1530/ ERC-18-0529.

\section{Declaration of interest}

The authors declare that there is no conflict of interest that could be perceived as prejudicing the impartiality of the research reported.

\section{Funding}

This work is supported by the National Natural Science Foundation of China (No. 81502551, 81773461) and the Health Technology Talent Project in Kunming (No. 2018-sw-107).

\section{Author contribution statement}

$F H, J L$ and J $C$ designed experiments and revised the paper. $F H, W L$, J $Y$ and $\mathrm{X} Z$ performed the experiments. $\mathrm{F} \mathrm{H}$ wrote the draft manuscript. $\mathrm{F} \mathrm{H}$, $W L, J L, M Z$ and $X J$ analyzed data. $X H, C M, W L$, J L and $L Y$ helped performed the experiments. $\mathrm{X} Z$ and $\mathrm{XH}$ assisted in the experiments.

\section{Acknowledgement}

The authors would like to thank all the patients involved in this study for their support.

\section{References}

Acloque H, Adams MS, Fishwick K, Bronner-Fraser M \& Nieto MA 2009 Epithelial mesenchymal transitions: the importance of changing cell state in development and disease. Journal of Clinical Investigation 119 1438-1449. (https://doi.org/10.1172/JCI38019)

Ballow D, Meistrich ML, Matzuk M \& Rajkovic A 2006 Sohlh1 is essential for spermatogonial differentiation. Developmental Biology 294 161-167. (https://doi.org/10.1016/j.ydbio.2006.02.027)

Birrer MJ, Johnson ME, Hao K, Wong KK, Park DC, Bell A, Welch WR, Berkowitz RS \& Mok SC 2007 Whole genome oligonucleotide-based array comparative genomic hybridization analysis identified fibroblast growth factor 1 as a prognostic marker for advanced-stage serous ovarian adenocarcinomas. Journal of Clinical Oncology 25 2281-2287. (https://doi.org/10.1200/JCO.2006.09.0795)

Davis FM, Stewart TA, Thompson EW \& Monteith GR 2014 Targeting EMT in cancer: opportunities for pharmacological intervention. Trends in Pharmacological Sciences 35 479-488. (https://doi. org/10.1016/j.tips.2014.06.006)

Dong R, Qiang W, Guo H, Xu X, Kim JJ, Mazar A, Kong B \& Wei JJ 2016 Histologic and molecular analysis of patient derived xenografts of high-grade serous ovarian carcinoma. Journal of Hematology and Oncology 9 92. (https://doi.org/10.1186/s13045-016-0318-6)

Ferlay J, Soerjomataram I, Ervik M, Dikshit R, Eser S, Mathers C, Rebelo M, Parkin DM, Forman D \& Bray F 2013 GLOBOCAN 2012 v1.0, Cancer Incidence and Mortality Worldwide: IARC CancerBase No. 11. Lyon, France: International Agency for Research on Cancer, 2017. (available at: http://globocan.iarc.fr)

Gao Q, Qiu SJ, Fan J, Zhou J, Wang XY, Xiao YS, Xu Y, Li YW \& Tang ZY 2007 Intratumoral balance of regulatory and cytotoxic T cells is associated with prognosis of hepatocellular carcinoma after resection. Journal of Clinical Oncology 25 2586-2593. (https://doi. org/10.1200/JCO.2006.09.4565)

Guo ST, Guo XY, Wang J, Wang CY, Yang RH, Wang FH, Li XY, Hondermarck H, Thorne RF, Wang YF, et al. 2017 MicroRNA-645 is an oncogenic regulator in colon cancer. Oncogenesis 6 e335. (https:// doi.org/10.1038/oncsis.2017.37)

Gyorffy B, Lanczky A \& Szallasi Z 2012 Implementing an online tool for genome-wide validation of survival-associated biomarkers in ovarian- https://erc bioscientifica com https://doi.org/10.1530/ERC-18-0529 (c) 2019 Society for Endocrinology Published by Bioscientifica Ltd. Printed in Great Britain 
cancer using microarray data from 1287 patients. Endocrine-Related Cancer 19 197-208. (https://doi.org/10.1530/ERC-11-0329)

Han F, Wang Z, Wu F, Liu Z, Huang B \& Wang D 2010 Characterization, phylogeny, alternative splicing and expression of Sox30 gene. $B M C$ Molecular Biology 11 98. (https://doi.org/10.1186/1471-2199-11-98)

Han F, Dong Y, Liu W, Ma X, Shi R, Chen H, Cui Z, Ao L, Zhang H, Cao J, et al. 2014 Epigenetic regulation of Sox30 is associated with testis development in mice. PLOS ONE 9 e97203. (https://doi. org/10.1371/journal.pone.0097203)

Han F, Liu W, Jiang X, Shi X, Yin L, Ao L, Cui Z, Li Y, Huang C, Cao J, et al. $2015 a$ SOX30, a novel epigenetic silenced tumor suppressor, promotes tumor cell apoptosis by transcriptional activating p53 in lung cancer. Oncogene 34 4391-4402. (https://doi.org/10.1038/onc.2014.370)

Han F, Liu W, Xiao H, Dong Y, Sun L, Mao C, Yin L, Jiang X, Ao L, Cui Z, et al. 2015b High expression of SOX30 is associated with favorable survival in human lung adenocarcinoma. Scientific Reports 5 13630. (https://doi.org/10.1038/srep13630)

Han F, Liu WB, Shi XY, Yang JT, Zhang X, Li ZM, Jiang X, Yin L, Li JJ, Huang CS, et al. 2018 SOX30 inhibits tumor metastasis through attenuating Wnt-signaling via transcriptional and posttranslational regulation of $\beta$-catenin in lung cancer. EBioMedicine 31 253-266. (https://doi.org/10.1016/j.ebiom.2018.04.026)

Kartalou M \& Essigmann JM 2001 Mechanisms of resistance to cisplatin. Mutation Research 478 23-43. (https://doi.org/10.1016/S00275107(01)00141-5)

Liu Y, Wang H, Zhong J, Wu C, Yang G, Zhong Y, Zhang J \& Tang A 2018 Decreased expression of SRY-box containing gene 30 is related to malignant phenotypes of human bladder cancer and correlates with poor prognosis. BMC Cancer 18 642. (https://doi.org/10.1186/ s12885-018-4560-x)

Lorusso D \& Pignata S 2017 Role of adjuvant chemotherapy in early stage endometrioid and clear cell ovarian cancer. Annals of Oncology 28 2909-2911. (https://doi.org/10.1093/annonc/mdx539)

Marsh S 2009 Pharmacogenomics of taxane/platinumtherapy in ovarian cancer. International Journal of Gynecological Cancer 19 S30-S34. (https://doi.org/10.1111/IGC.0b013e3181c10513)

Nieto MA, Huang RY, Jackson RA \& Thiery JP 2016 EMT: 2016. Cell 166 21-45. (https://doi.org/10.1016/j.cell.2016.06.028)

Osaki E, Nishina Y, Inazawa J, Copeland NG, Gilbert DJ, Jenkins NA, Ohsugi M, Tezuka T, Yoshida M \& Semba K 1999 Identification of a novel Sry-related gene and its germ cell-specific expression. Nucleic Acids Research 27 2503-2510. (https://doi.org/10.1093/ nar/27.12.2503

Oseledchyk A, Leitao MM Jr, Konner J, O'Cearbhaill RE, Zamarin D, Sonoda Y, Gardner GJ, Long Roche K, Aghajanian CA, Grisham RN, et al. 2017 Adjuvant chemotherapy in patients with Stage I endometrioid or clear cell ovarian cancer in the platinum era: a surveillance, epidemiology, and end results Cohort Study, 20002013. Annals of Oncology 28 2985-2993. (https://doi.org/10.1093/ annonc/mdx525)

Siegel R, Naishadh D \& Jemal A 2013 Cancer statistics, 2013. CA: A Cancer Journal for Clinicians 63 11-30. (https://doi.org/10.3322/ caac. 21166)

Siegel RL, Miller KD \& Jemal A 2016 Cancer statistics, 2016. CA: A Cancer Journal for Clinicians 66 7-30. (https://doi.org/10.3322/ caac.21332)

Thiery JP \& Sleeman JP 2006 Complex networks orchestrate epithelialmesenchymal transitions. Nature Reviews Molecular Cell Biology $\mathbf{7}$ 131-142. (https://doi.org/10.1038/nrm1835)

Thiery JP, Acloque H, Huang RY \& Nieto MA 2009 Epithelialmesenchymal transitions in development and disease. Cell 139 871-890. (https://doi.org/10.1016/j.cell.2009.11.007)

Tsofack SP, Meunier L, Sanchez L, Madore J, Provencher D, MesMasson AM \& Lebel M 2013 Low expression of the X-linked ribosomal protein S4 in human serous epithelial ovarian cancer is associated with a poor prognosis. BMC Cancer 13 303. (https://doi. org/10.1186/1471-2407-13-303)

Vaughan S, Coward JI, Bast RC Jr, Berchuck A, Berek JS, Brenton JD, Coukos G, Crum CC, Drapkin R, Etemadmoghadam D, et al. 2011 Rethinking ovarian cancer: recommendations for improving outcomes. Nature Reviews Cancer 11 719-725. (https://doi. org/10.1038/nrc3144)

Verhaak RG, Tamayo P, Yang JY, Hubbard D, Zhang H, Creighton CJ, Fereday S, Lawrence M, Carter SL, Mermel CH, et al. 2013 Prognostically relevant gene signatures of high-grade serous ovarian carcinoma. Journal of Clinical Investigation 123 517-525. (https://doi. org/10.1172/JCI65833)

Wei W, Mok SC, Oliva E, Kim SH, Mohapatra G \& Birrer MJ 2013 FGF18 as a prognostic and therapeutic biomarker in ovarian cancer. Journal of Clinical Investigation 123 4435-4448. (https://doi.org/10.1172/ JCI70625)

Ye X \& Weinberg RA 2015 Epithelialmesenchymal plasticity: a central regulator of cancer progression. Trends in Cell Biology 25 675-686. (https://doi.org/10.1016/j.tcb.2015.07.012)

Yilmaz M \& Christofori G 2009 EMT, the cytoskeleton, and cancer cell invasion. Cancer Metastasis Reviews 28 15-33. (https://doi. org/10.1007/s10555-008-9169-0)

Zhou JD, Wang YX, Zhang TJ, Li XX, Gu Y, Zhang W, Ma JC, Lin J \& Qian J 2018 Identification and validation of SRY-box containing gene family member SOX30 methylation as a prognostic and predictive biomarker in myeloid malignancies. Clinical Epigenetics 10 92. (https://doi.org/10.1186/s13148-018-0523-y)

Received in final form 15 December 2018

Accepted 3 January 2019

Accepted Preprint published online 3 January 2019 (c) 2019 Society for Endocrinology Published by Bioscientifica Ltd. Printed in Great Britain 